\title{
Development of a DNA Macroarray for the Detection and Identification of Fungal Pathogens Causing Decline of Young Grapevines
}

\author{
J. R. Úrbez-Torres, P. Haag, P. Bowen, T. Lowery, and D. T. O’Gorman
}

Agriculture and Agri-Food Canada, Science \& Technology Branch, Pacific Agri-Food Research Centre, Summerland, British Columbia V0H 1Z0, Canada.

Accepted for publication 30 April 2015.

\begin{abstract}
Úrbez-Torres, J. R., Haag, P., Bowen, P., Lowery, T., and O'Gorman, D. T. 2015. Development of a DNA macroarray for the detection and identification of fungal pathogens causing decline of young grapevines. Phytopathology 105:1373-1388.

Young vine decline (YVD) is a complex disease caused by at least 51 different fungi and responsible for important economic losses to the grapevine industry worldwide. YVD fungi are known to occur in planting material. Hence, detection prior to planting is critical to assure longevity of newly established vineyards. A DNA macroarray based on reverse dot-blot hybridization containing 102 oligonucleotides complementary to portions of the $\beta$-tubulin region was developed for detection of YVD fungi. Specificity

of the array was first evaluated against 138 pure fungal cultures representing 72 different taxa from nine genera, including 37 YVD species. In total, 61 species, including 34 YVD pathogens, were detected and identified by the array. The detection limit of the array was below $0.1 \mathrm{pg}$ of genomic DNA. The array was validated against artificially inoculated canes and soil and commercial planting material, with the latter showing a high incidence of YVD fungi in nursery plants otherwise not detected by traditional plating and culturing. This DNA array proved to be a rapid and specific tool to simultaneously detect and identify most YVD fungi in a single test, which has the potential to be used in commercial diagnostics or by the grapevine nursery industry to determine the health status of the planting material.
\end{abstract}

Young vine decline (YVD), caused by the grapevine trunk diseases (GTD) black foot and Petri disease, occurs wherever grapes are grown and is the primary biotic cause of decline and consequent mortality in young vineyards ( $\leq 6$ years old) (Agustí-Brisach and Armengol 2013; Gramaje and Armengol 2011). YVD symptoms are observed within 5 years of planting and first recognized in the field by an overall reduction of vigor, which includes delayed, stunted, or lack of spring growth; short shoot internodes; and small chlorotic leaves. YVD vascular symptoms are primarily observed at the basal end of the rootstock or self-rooted cultivar and are characterized by light-brown or necrotic tissue of the xylem vessels. Belowground, black-foot-infected grapevines can show sunken necrotic root lesions and a reduction in root biomass and root hairs. Though several other biotic and abiotic factors are known to be involved in the poor performance of young vines (Stamp 2001), it is currently well known that the introduction of infected planting material represents the primary cause of YVD rapid expansion (Gimenez-Jaime et al. 2006; Halleen et al. 2003). Incidence of YVD has dramatically increased since the mid-1990s and is currently worsening in nearly all grapevine-growing countries worldwide (Gramaje and Armengol 2011). Accordingly, YVD has been routinely shown to affect vines in many young vineyards around the world, with infection rates of 5 to $15 \%$ causing important economic losses as a result of replanting (Eskalen et al. 2007; Scheck et al. 1998; Sidoti et al. 2000; Úrbez-Torres et al. 2014a,b). Additionally, over $50 \%$ infection rates have been reported to occur in new established vineyards within the first year of planting in France

Corresponding author: J. R. Úrbez-Torres;

E-mail address: joseramon.urbeztorres@agr.gc.ca

*The $\boldsymbol{e}$-Xtra logo stands for "electronic extra" and indicates that four supplementary figures are published online.

http://dx.doi.org/10.1094/PHYTO-03-15-0069-R

(C) Her Majesty the Queen in Right of Canada, as represented by the Minister of Agriculture and Agri-Food Canada, 2015.
(Maluta and Larignon 1991), Australia (Pascoe and Cottral 2000), Spain (J. Armengol, personal communication), and, most recently, in Canada (Úrbez-Torres et al. 2014a,b). Because a full crop is usually reached after 4 to 5 years of planting, there is no doubt that infection of this magnitude, particularly before any cash return is obtained, causes unsustainable economic losses to growers. A recent study concluded that the overall economic impact of GTD could be estimated as being over US $\$ 1.5$ billion worldwide, a cost attributed to the replacement of only $1 \%$ of the worldwide plants per year (Hofstetter et al. 2012). However, this impact appears to be underestimated according to the information provided by the aforementioned studies, which reveal GTD and, particularly, decline and mortality of young vines to be a major threat to the sector's future economic sustainability.

To date, 51 fungi are known to be associated with YVD of grapevines. Eighteen of these species belong to the genera Campylocarpon Halleen, Schroers \& Crous, Cylindrocadiella Boesewinkel, Dactylonectria L. Lombard \& Crous, and Ilyonectria P. Chaverri \& C. Salgado (anamorph: 'Cylindrocarpon' Wollenweber) and are responsible for causing black foot disease (Agustí-Brisach and Armengol 2013, Lombard et al. 2014). Petri disease is primarily caused by the ascomycetous fungi Phaeomoniella chlamydospora (W. Gams, Crous, M. J. Wingf. \& Mugnai) Crous \& W. Gams and Togninia minima (Tul. \& C. Tul.) Berl. (anamorph: Phaeoacremonium aleophilum W. Gams, Crous, M. J. Wingfield \& Mugnai) (Crous et al. 1996; Crous and Gams 2000; Mostert et al. 2006). However, up to 26 other species of Togninia or Phaeoacremonium have been reported to occur in symptomatic vines (Úrbez-Torres et al. 2014b). Moreover, Cadophora luteo-olivacea (J. F. H. Beyma) T. C. Harr. \& McNew, C. melinii Nannf. and the recently described C. novieboraci Travadon, Lawrence, Rooney-Latham, Gubler, Wilcox, Rolshausen, \& K. Baumgartner; C. orientoamericana Travadon, Lawrence, Rooney-Latham, Gubler, Wilcox, Rolshausen, \& K. Baumgartner; and C. spadicis (Prodi, Sandalo, Tonti, Nipoti \& A. Pisi) Travadon, Lawrence, Rooney-Latham, Gubler, Wilcox, Rolshausen, \& $\mathrm{K}$. Baumgartner are known to occur on grapevine planting 
material (Gramaje et al. 2011, Travadon et al. 2015). Until recently, black foot and Petri disease were considered to be two separate GTD responsible for the decline of young vines. However, it is currently well accepted that they constitute a disease complex, in which several species from the aforementioned genera can often coexist in the same symptomatic plant (Gramaje and Armengol 2011; Úrbez-Torres et al. 2014a,b).

Identification and characterization of fungi associated with YVD have long been based on phenotypic characteristics, including colony growth on enriched media and micromorphology of reproductive structures (Crous et al. 1996; Crous and Gams 2000; Scheck et al. 1998). However, the taxonomic complexity of the different genera associated with YVD, which includes considerable overlapping in the morphology (size, shape, and color) of microscopic structures, has made the sole use of culture-based morphological approaches insufficient to accurately discriminate among many of these species (Cabral et al. 2012a,b; Mostert et al. 2006). Accordingly, fungi known to cause YVD are now identified by means of partial DNA sequences from different genes and construction of multigene phylogenies (Gramaje et al. 2009, 2011; Halleen et al. 2004; Mostert et al. 2006; Úrbez-Torres et al. 2014a,b). The multigene phylogenetic approach has not only allowed a better discrimination among YVD fungi but has also contributed to expand the knowledge of the different fungal taxa associated with this syndrome by the discovery of cryptic species otherwise not possible to be identified phenotypically (Cabral et al. 2012a,b). Detection and identification of some YVD fungi have also been achieved using other molecular techniques, including polymerase chain reaction (PCR) restriction fragment length polymorphism (RFLP) markers (Tegli et al. 2000); species-specific primers used in single, multiplex, nested, co-operational-, or real-time PCR-based assays (Agustí-Brisach et al. 2014; Alániz et al. 2009; Aroca and Raposo 2007; Martos et al. 2011; Overton et al. 2004); and immunological detection (Fleurat-Lessard et al. 2010, 2014). Though significant advances have been made on molecular identification and diagnosis of YVD fungi during the last decade, all these PCR-based techniques are designed for the identification of only one or a small number of species at a time. Accordingly, considering that a wide range of fungal species belonging to taxonomically unrelated genera are involved in the YVD complex and that many of these can be found in the nurserypropagated material prior to planting in commercial sites, there is a critical need for a diagnostic approach capable of rapid and simultaneous identification and differentiation of a much larger number of YVD fungi at once.

DNA macroarrays were first developed in the medical field in the late 1980s to screen for human genetic disorders (Kawasaki et al. 1993; Saiki et al. 1989). Since then, they have been used in ecological studies to determine microbial populations (Voordouw et al. 1993) and in the area of food safety to identify foodborne pathogens (Call et al. 2001). However, it has been in agriculture where DNA macroarray systems have primarily been developed and implemented during the last decade, mainly because of their potential for simultaneous identification of many different microorganisms in a single test. Accordingly, DNA macroarrays are currently available for detection and identification of a broad range of plant pathogens infecting both annual and perennial crops, including bacteria (Fessehaie et al. 2003), fungi, and oomycetes (Lévesque et al. 1998; Lievens et al. 2003; Sholberg et al. 2005; Tambong et al. 2006; Zhang et al. 2007, 2008; Chen et al. 2013), and viruses (Maoka et al. 2010; Minutillo et al. 2012; Thompson et al. 2012). DNA macroarray technology is based on the design of species-specific oligonucleotide probes (15 to 30 bases long) that are fixed on a nylon or nitrocellulose membrane and hybridized with homologous PCR-amplified and -labeled target DNA sequences, which can then be detected (Zhang et al. 2008). Accordingly, the objectives of this study were to (i) design and develop a DNA macroarray system based on the reverse dot-blot hybridization technique for rapid and accurate detection and identification of
YVD fungi and (ii) validate the array against artificially inoculated plant and soil material as well as against commercial grapevine plants.

\section{MATERIAL AND METHODS}

Fungal species and isolates. In total, 138 fungal isolates representing 72 different species from nine genera were used in this study. Fungal isolates included 37 known YVD pathogens from different geographical locations as well as other taxa within the same genera from different hosts (Table 1). The ex-type specimen of each taxon used in this study was included when possible and they were obtained from the Centraalbureau Schimmelcultures (CBS, Utrecht, The Netherlands), Department of Agriculture Ottawa Mycology (DAOM) (Agriculture and Agri-Food Canada, Ottawa, ON, Canada) and International Collection for Microorganisms from Plants (Lincoln, New Zealand) fungal collections (Table 1). Revitalization of the different ex-type isolates was conducted following collections' protocols. All fungal isolates were grown on 85-mmdiameter petri plates containing $4 \%$ potato dextrose agar (PDA) (Difco Laboratories, Detroit) and incubated at $20^{\circ} \mathrm{C}$ in the dark for at least 10 days before total genomic DNA was extracted. Additionally, genomic DNA from several isolates was directly provided to our laboratory by Dr. M. Tello (Instituto Madrileño de Investigación y Desarrollo Rural, Agrario y Alimentario, IMIDRA, Alcalá de Henares, Spain), Dr. P. Rolshausen (Department of Botany and Plant Sciences, University of California-Riverside), and Dr. W. D. Gubler (Plant Pathology Department, University of California-Davis) following the protocol described by Owens and Szalanskij (2005) (Table 1).

Amplification of the $\beta$-tubulin region and sequence analysis. Total genomic DNA was extracted from pure fungal colonies growing on PDA, as previously described (Úrbez-Torres et al. 2014b). Dried DNA from the rest of the isolates sent to our laboratory was rehydrated following previously described protocol (Owens and Szalanskij 2005). DNA of each isolate was stored at $-20^{\circ} \mathrm{C}$ until needed. Amplification of part of the $\beta$-tubulin (TUB) region was performed with forward $(\mathrm{Bt} 2 \mathrm{a})$ and reverse $(\mathrm{Bt} 2 \mathrm{~b})$ primers (Glass and Donaldson 1995), as previously described (Úrbez-Torres et al. 2014b). Amplified products were purified using a QIAquick PCR purification Kit (Qiagen Inc., Valencia, CA) and amplicons were sequenced in the NAPS Unit at the Michael Smith Laboratories, University of British Columbia, Vancouver, Canada. Sequences were manually edited and assembled using Lasergene SeqMan Pro (version 9.1.1.4; DNASTAR Inc., Madison, WI). DNA sequences obtained in this study and not available in a public database were deposited in GenBank (National Center for Biotechnology Information, Bethesda, MD) (Table 1).

Amplification of the TUB region for the different Cadophora spp. included in this study was not possible using $\mathrm{Bt} 2 \mathrm{a}$ and $\mathrm{Bt} 2 \mathrm{~b}$ primers alone due to multiple nonspecific amplification products. Accordingly, a nested PCR was conducted to reduce nonspecific binding by utilizing an alternative outside primer pair. The first PCR, with outer primers T1 and Bt1b (Glass and Donaldson 1995), was conducted following the protocol described by Úrbez-Torres et al. (2014b), with the only variant of an extension of $72^{\circ} \mathrm{C}$ for $2 \mathrm{~min}$ instead $90 \mathrm{~s}$. Amplified products $(2 \mu \mathrm{l})$ were used for a second amplification using the inner primers $\mathrm{Bt} 2 \mathrm{a}$ and $\mathrm{Bt} 2 \mathrm{~b}$, following the previously described protocol (Úrbez-Torres et al. 2014b), with the only variant of initial denaturation of $4 \mathrm{~min}$ at $94^{\circ} \mathrm{C}$. DNA consensus sequences of the different amplified products were obtained as described above. Nested PCR was not required to validate the DNA macroarray against Cadophora spp.

Consensus sequences were searched in GenBank using the Basic Local Alignment Search Tool (BLAST) to confirm the identity of each isolate and to identify homologous sequences in the database. Consensus sequences from each of the species used in this study were aligned using the computer software BioEdit Sequence Alignment Editor version 7.1.3.0 (Hall 1999). Alignments were 
visually inspected and imported into Molecular Evolutionary Genetics Analysis version 5.1 (MEGA5) (Tamura et al. 2011). Phylogenetic analyses and tree building was conducted as previously described (Úrbez-Torres et al. 2014b). Maximum parsimony (MP) phylogenetic analyses were generated to assess intraspecific (within-species) and interspecific (between-species) variation for each fungal group, including Cadophora, Campylocarpon-CylindrocarponDactylonectria-Ilyonectria-Neonectria, Phaeoacremonium-Togninia, and Phaeomoniella. Mean intraspecific variation was calculated in MEGA5 for clades containing at least two isolates per taxon.

Oligonucleotide probes design. Sequence alignments of the isolates used in this study plus those from related taxa retrieved from GenBank were analyzed in BioEdit in order to visually identify regions exhibiting unique polymorphisms (at least one mismatch). These regions were marked as potential areas for the development of species-specific probes to be used in the DNA macroarray. Final probe selection and design were conducted using Oligo Explorer 1.5 (Gen Link Inc., Hawthorne NY) to ensure uniform melting temperatures and the absence of duplex formations. Specificity of each probe was confirmed by conducting BLAST searches of probe sequences in the GenBank database to avoid selecting DNA homologous to other species. Multiple probes with comparable melting temperatures $\left(60 \pm 1^{\circ} \mathrm{C}\right)$ were designed for each fungal species. The name of each probe was designated with the species name, location within the amplicon sequence, and length of the probe. Positive control probes designed to detect DNA from all fungal species were a modification of universal primers $\mathrm{Bt} 2 \mathrm{a}$ and $\mathrm{Bt} 2 \mathrm{~b}$. Internal controls that differed from primers $\mathrm{Bt} 2 \mathrm{a}$ and $\mathrm{Bt} 2 \mathrm{~b}$ in one or two bases were also tested on the array. Negative controls were sterile water and the spotting buffer (Zhang et al. 2008).

DNA array construction. Oligonucleotide probes were ordered from Integrated DNA Technologies Inc. (San Diego, CA) with a 5'-end amine-modification to secure immobilization on the Immodyne ABC nylon membrane (PALL Europe Ltd., Portsmouth, England) used to construct the array. Probes were rehydrated in sterile $10 \mathrm{mM}$ Tris, diluted to a final concentration of $40 \mu \mathrm{M}$ in sodium bicarbonate buffer $(0.5 \mu \mathrm{M}, \mathrm{pH} 8.4)$ plus $0.004 \%$ bromophenol blue (spotting buffer), then placed in individual wells in a sterile Nalge Nuc's 384well microplate (V\&P Scientific Inc., San Diego, CA). Probes were arranged in four separate blocks, with each block targeting all different species within the same genus or genera, including Phaeomoniella (block 1) Phaeoacremonium-Togninia (block 2), CampylocarponCylindrocarpon-Dactylonectria-Ilyonectria-Neonectria (block 3 ), and Cadophora (block 4). Probes were spotted on previously cut ( 10 by $12 \mathrm{~cm}$ ) nylon membranes using a VP 384 Library Copier (V\&P Scientific Inc.). Each probe was spotted in duplicates horizontally side by side and multiple membranes were spotted for each run. Spotted membranes were air dried for $10 \mathrm{~min}$, transferred into a glass tray containing the blocking solution $(2 \times \mathrm{SCC}[1 \times \mathrm{SSC}$ is $0.15 \mathrm{M} \mathrm{NaCl}$ plus $0.015 \mathrm{M}$ sodium citrate] [pH 7.0)], $0.5 \%$ casein [Alfa Aesar, Heysham, Lancashire, UK] [g/ml], and 0.05\% [vol/vol] Tween-20), and incubated for a minimum of $30 \mathrm{~min}$ on an orbital shaker set on low. Following blocking, membranes were rinsed twice in $2 \times$ SCC for immediate use.

DNA-labeling, hybridization, and detection from pure cultures. DNA from each of the isolates used in this study was amplified with primers $\mathrm{Bt} 2 \mathrm{a}$ and $\mathrm{Bt} 2 \mathrm{~b}$, as previously described, and labeled with digoxigenin (DIG)-11-dUTP alkali-stable (Roche Diagnostics, Laval, QC, Canada) in the PCR. Spotted membranes were first prehybridized in hybridization buffer $(\mathrm{HB})(6 \times \mathrm{SCC}, 0.1 \%$ $\mathrm{N}$-lauroyl-sarcosine [Sigma-Aldrich, St. Louis], 0.02\% sodium dodecyl sulfate [SDS] [Sigma-Aldrich], and 1\% skim milk powder $[\mathrm{g} / \mathrm{ml}])$ at $60^{\circ} \mathrm{C}$ for at least $1 \mathrm{~h}$. Target-labeled DNA was denatured by mixing $2 \mu \mathrm{l}$ of DIG-dUTP-labeled PCR product with $8 \mathrm{ml}$ of $\mathrm{HB}$ in 15-ml sterile centrifuge tubes (VWR International, LLC, Randor, PA) in boiling water for $10 \mathrm{~min}$. Tubes were transferred to a $65^{\circ} \mathrm{C}$ water bath. Single membranes were then added to the tubes and hybridized overnight at $60^{\circ} \mathrm{C}$ in a Teck Start Jr. hybridization oven (Bio/Can Scientific, Mississauga, ON, Canada). Membranes were removed from the tubes and washed twice for $15 \mathrm{~min}$ in $2 \times$ SSC plus $0.1 \%$ SDS buffer. Membranes were placed in glass hybridization tubes and washed twice for 20 min with stringency buffer (4x SSC plus $0.1 \% \mathrm{SDS}$ ) at $60^{\circ} \mathrm{C}$ in the hybridization oven. Membranes were removed from the glass hybridization tubes and washed on a shaker for $5 \mathrm{~min}$ with washing buffer (WB) $(0.5 \mathrm{M}$ maleic acid, $0.75 \mathrm{M}$ sodium chloride, $8 \%$ sodium hydroxide pellets [g/liter], and $3 \%$ Tween-20). Membranes were then incubated for a minimum of 20 min in WB plus $1 \%$ skim milk powder. After this step, membranes were incubated in WB plus 1\% skim milk powder and a 1:25000 dilution of anti-DIG alkaline phosphatase conjugate (Roche Diagnostics $\mathrm{GmbH}$, Mannheim, Germany) for exactly 30 min under constant agitation. Membranes were washed twice for 15 min in WB and equilibrated for at least $5 \mathrm{~min}$ in $1 \times$ Tris-hydrogen chloride $(0.5 \mathrm{M})$ plus sodium chloride $(0.5 \mathrm{M})$ buffer. Membranes were incubated again in the same buffer with a 1:1000 dilution of CDP-Start (Roche Diagnostics $\mathrm{GmbH}$ ) for a minimum of 5 min. Membranes were sealed in commercial plastic wrap using a heat sealing machine and immediately exposed to X-ray film (Blue Sensitive MB-1; Medtech Marketing Ltd., Burnaby, BC, Canada) for 90 min. DIG-labeled PCR products that hybridized appeared as dots of varying gray intensities. Reproducibility of the DNA macroarray was evaluated with three independent repetitions per fungal isolate. X-ray films were scanned on an Epson Expression 1680 scanner (Epson Canada Ltd., Markham, ON, Canada) using the transparency mode. ImageQuant TL Array Analysis Software 8.1 (General Electric, Healthcare Life Science, Piscataway, NJ) was used to read individual hybridization signals. Dot signal intensity data for each isolate were recorded as the mean of three values from three separate runs.

Array sensitivity. In order to determine the detection limit of the array, genomic DNA of Phaeomoniella chlamydospora isolate CBS 117179 (initial [DNA]: $42.01 \mathrm{ng} / \mu \mathrm{l}$ ) and $T$. minima isolate CBS 631.94 (initial [DNA]: $72.22 \mathrm{ng} / \mu \mathrm{l}$ ) was diluted to nine 10-fold dilution series and amplified using $\mathrm{Bt} 2 \mathrm{a}$ and $\mathrm{Bt} 2 \mathrm{~b}$ primers and DIG11-dUTP, as previously described. DIG-labeled PCR amplicons were hybridized against homologous probes and results were converted to grayscale values, as previously described. Three independent repetitions of the assay were conducted for each isolate.

Detection of YVD fungi from artificially and naturally infected samples. Detection from inoculated detached grapevine dormant canes. The application of the DNA macroarray was first validated against artificially inoculated 'Chardonnay' dormant canes from a previous study aimed to complete Koch's postulates of 23 isolates representing 12 different fungal species isolated from YVDsymptomatic grapevines in British Columbia (Úrbez-Torres at al. 2014a,b). Six canes per fungal isolate were inoculated using mycelium plugs from active growing colonies and six additional canes were inoculated with noncolonized PDA plugs for negative controls. For the purpose of this study, canes inoculated with Ilyonectria liriodendri (DAOM 242317 and DAOM 242318), Dactylonectria macrodidyma (DAOM 242320 and DAOM 242321), P. chlamydospora (DAOM 242367 and DAOM 242368), and T. minima (DAOM 242326 and DAOM 242360) were selected. At 31 days after inoculation, a wood section of approximately $1 \mathrm{~cm}$ in length was collected $0.5 \mathrm{~cm}$ below the point of inoculation. After surface sterilization ( $70 \%$ ethanol for $10 \mathrm{~s}$ ), wood sections were cut in half. One half was used to attempt recovering the inoculated fungus by plating the necrotic tissue on PDA, as previously described (Urbez-Torres at al. 2014a,b). The other half was used to validate the DNA macroarray. Wood tissue was sectioned in small pieces using a sterile scalpel and total genomic DNA was extracted using the FastDNA SPIN KIT (MP Biomedicals, LLC, Solon, OH) following the manufacturer's instructions. The DNA was amplified and labeled with DIG-11-dUTP and hybridized as detailed above. 
TABLE 1. Fungal species from Vitis vinifera and other hosts identified and confirmed by morphological and molecular approaches and used in this study

\begin{tabular}{|c|c|c|c|}
\hline Species $^{\mathrm{a}}$ & Isolate $^{b}$ & Host, origin, collector ${ }^{\mathrm{c}}$ & TUB $^{\mathrm{d}}$ \\
\hline Cadophora fastigiata & CBS 226.30 & Pinus strobus, Canada, C. W. Fritz & $K R 260460$ \\
\hline C. finlandica & CBS 444.86 & P. sylvestris, Finland, C. J. K. Wang & $K R 260463$ \\
\hline C. gregata & CBS 132.51 & Glycine $\max$, Missouri, D. W. Chamberlain & $K R 260459$ \\
\hline C. hiberna & CBS 110521 & Robinia pseudoacacia, Pennsylvania, G. F. Bills & $K R 260464$ \\
\hline C. luteo-olivacea* & CBS 357.51 & Malus sylvestris, Italy, G. Goidánich & KF764682 \\
\hline C. luteo-olivacea & DAOM 242316 & Vitis riparia $\times V$. rupestris, British Columbia, J. R. Úrbez-Torres & KF764647 \\
\hline C. luteo-olivacea & DAOM 242319 & V. vinifera, British Columbia, P. Haag \& D. T. O’Gorman & KF764648 \\
\hline C. luteo-olivacea & PARC313 & V. vinifera, British Columbia, J. R. Úrbez-Torres & KF764649 \\
\hline C. luteo-olivacea & PARC314 & V. vinifera, British Columbia, J. R. Úrbez-Torres & KF764650 \\
\hline C. malorum & CBS 266.31 & n.a., n.a., F. D. Heald & KR260461 \\
\hline C. melinii* & CBS 268.33 & Lumber and wood pulp, Sweden, E. Melin & KR260462 \\
\hline Campylocarpon fasciculare* & CBS 112613 & V. vinifera, South Africa, F. Halleen & AY677221 \\
\hline C. pseudofasciculare* & CBS 112679 & V. vinifera, South Africa, F. Halleen & AY677214 \\
\hline Cylindrocarpon ianthothele var. majus & CBS 287.92 & Soil in primary forest, Brazil, D. Attili & $K R 260456$ \\
\hline C. ianthothele var. minus & CBS 266.36 & n.a., Germany, H. W. Wollenweber & $K R 260457$ \\
\hline C. cylindroides & CBS 503.67 & Abies alba, Norway, F. Roll-Hansen & JF735436 \\
\hline C. obtusisporium & CBS 183.36 & Solanum tuberosum, Germany, H. W. Wollenweber & AM419085 \\
\hline C. olidum var. olidum & CBS 215.67 & Rooting rhizome, Germany, W. Gerlach & $K R 260458$ \\
\hline Cylindrocarpon sp. & Cyl3 $3^{\text {DNA }}$ & Vitis hybrid, Québec, P. Rolshausen & HQ338505 \\
\hline C. theobromicola & CBS 218.67 & Theobroma cacao, Papua New Guinea, P. G. Hicks & EF607062 \\
\hline Dactylonectria macrodidyma* & CBS 112615 & V. vinifera, South Africa, F. Halleen & AY677233 \\
\hline D. macrodidyma & DAOM 242320 & V. riparia $\times V$. rupestris, British Columbia, J. R. Úrbez-Torres & KF511974 \\
\hline D. macrodidyma & DAOM 242321 & V. riparia $\times V$. rupestris, British Columbia, J. R. Úrbez-Torres & KF511975 \\
\hline D. macrodidyma & USSO $146^{\mathrm{DNA}}$ & V. vinífera, California, E. Petit & AY997620 \\
\hline D. macrodidyma & USSL152 & V. vinífera, California, E. Petit & AY997573 \\
\hline D. torresensis* & DAOM 242324 & V. riparia $\times V$. rupestris, British Columbia, P. Haag \& D. T. O’Gorman & KF511978 \\
\hline D. torresensis & DAOM 242325 & $V$. riparia $\times V$. rupestris, British Columbia, P. Haag \& D. T. O'Gorman & KF511979 \\
\hline D. torresensis & PARC142 & $V$. riparia $\times V$. rupestris, British Columbia, J. R. Úrbez-Torres & KF511980 \\
\hline D. pauciseptata* & CBS 120171 & Vitis sp., Slovenia, M. Žerjav & EF607066 \\
\hline D. pauciseptata & DAOM 242314 & $V$. berlandieri $\times V$. riparia, British Columbia, P. Haag \& D. T. O’Gorman & KF511968 \\
\hline D. pauciseptata & DAOM 242315 & V. riparia $\times V$. rupestris, British Columbia, J. R. Úrbez-Torres & KF511969 \\
\hline Ilyonectria europaea* & CBS 102892 & Phragmites australis, Germany, W. Leibinger & JF735422 \\
\hline I. gamsii & CBS 940.97 & Soil, The Netherlands, J. T. Poll & AM419089 \\
\hline I. liriodendri* & CBS 110.81 & Liriodendron tulipifera, California, J. D. MacDonald \& E. E. Butler & DQ178170 \\
\hline I. liriodendra & CBS 112595 & V. vinifera, South Africa, F. Halleen & AY677247 \\
\hline I. liriodendra & CBS 112599 & V. vinifera, France, n.a. & AY677243 \\
\hline I. liriodendra & DAOM 242317 & V. vinifera, British Columbia, P. Haag \& D. T. O’Gorman & KF511971 \\
\hline I. liriodendra & DAOM 242318 & V. riparia $\times V$. rupestris, British Columbia, J. R. Úrbez-Torres & KF511972 \\
\hline I. liriodendra & PARC60 & V. vinifera, British Columbia, P. Haag \& D. T. O’Gorman & KF511970 \\
\hline I. liriodendra & PARC393 & V. berlandieri $\times V$. riparia, British Columbia, P. Haag \& D. T. O’Gorman & KF511973 \\
\hline I. liriodendra & USME1 $16^{\text {DNA }}$ & V. vinífera, California, E. Petit & AY997568 \\
\hline I. liriodendra & USS0150 DNA & V. vinifera, California, E. Petit & AY997570 \\
\hline I. liriodendra & Cyl4 DNA & $V$. hybrid, Québec, P. Rolshausen & HQ338506 \\
\hline I. liriodendra & Cyl6 & $V$. hybrid, Québec, P. Rolshausen & HQ338508 \\
\hline I. radicicola & CBS 264.65 & Cyclamen persicum, Sweden, L. Nilsson & AY677256 \\
\hline I. radicicola & Cyl2 DNA & Vitis hybrid, Québec, P. Rolshausen & HQ338504 \\
\hline I. robusta* & CBS 773.83 & Water in aquarium, The Netherlands, J. Hemelraad & AY677254 \\
\hline I. robusta & DAOM 242322 & V. vinifera, British Columbia, J. R. Úrbez-Torres & KF511976 \\
\hline I. robusta & DAOM 242323 & V. riparia $\times V$. rupestris, British Columbia, J. R. Úrbez-Torres & KF511977 \\
\hline Neonectria faginata & CBS 217.67 & Fagus grandifolia, Canada, G. L. Stone & JF268730 \\
\hline Neonectria sp. & Cyl9DNA & Vitis hybrid, Québec, P. Rolshausen & HQ338511 \\
\hline Phaeoacremonium alvesii* & CBS 110034 & Human, Brazil, S. H. Alves & AY579301 \\
\hline P. alvesii & A $81^{\text {DNA }}$ & V. vinifera, California, S. Rooney-Latham & n.a. \\
\hline P. amstelodamense & CBS 110627 & Human, The Netherlands, J. Bruins & AY579295 \\
\hline P. angustius* & CBS 249.95 & V. vinifera, California, P. Larignon & AF246814 \\
\hline P. angustius & $\mathrm{A} 155^{\mathrm{DNA}}$ & V. vinifera, California, S. Rooney-Latham & n.a. \\
\hline P. armeniacum* $^{*}$ & ICMP 17421 & Vitis sp., New Zealand, B. S. Weir & EU596526 \\
\hline P. australiense* & CBS 113589 & V. vinifera, Australia, T. Knaggs & AY579296 \\
\hline P. canadense* & DAOM 242366 & V. riparia $\times V$. rupestris, British Columbia, J. R. Úrbez-Torres & KF764651 \\
\hline P. canadense & PARC392 & V. vinifera, British Columbia, J. R. Úrbez-Torres & KF764652 \\
\hline P. canadense & PARC394 & V. vinifera, British Columbia, J. R. Úrbez-Torres & KF764653 \\
\hline P. cinereum* & CBS 123909 & V. vinifera, Iran, H. Mohammandi & FJ517161 \\
\hline P. croatiense* $^{*}$ & CBS 123037 & V. vinifera, Croatia, B. Cvjetković & EU863482 \\
\hline P. fuscum & CBS 120856 & Prunus salicina, South Africa, U. Damm & EU128098 \\
\hline P. globosum* & ICMP 16988 & Vitis sp., New Zealnd, B. S. Weir & EU596525 \\
\hline
\end{tabular}

(continued on next page)

\footnotetext{
a Asterisks (*) indicate fungal species reported to occur in grapevines (Vitis vinifera or Vitis sp.).

${ }^{\mathrm{b}}$ Isolate numbers in bold represent ex-type specimens. CBS = Centraalbureau Schimmelcultures, Utrecht, The Netherlands; ICMP = International Collection for Microorganisms from Plants, Lincoln, New Zealand; DAOM = Department of Agriculture Ottawa Mycology, Ottawa, Canada; PARC = Pacific Agri-Food Research Centre Fungal Collection, Summerland, British Columbia, Canada; and UCD = Plant Pathology Department, University of California Davis, Davis). DNA: Isolates from which only DNA was provided.

${ }^{c}$ Locations of origin include the states of Missouri, Pennsylvania, California, Maryland, Texas, and Arkansas in the United States and provinces of British Columbia, Québec, and Ontario in Canada.

${ }^{\mathrm{d}}$ GenBank accession numbers; TUB $=\beta$-tubulin. Numbers in italics were generated in this study; n.a. indicates sequence not generated in this study and not available in GenBank.
} 
TABLE 1. (continued from preceding page)

\begin{tabular}{|c|c|c|c|}
\hline Species $^{\mathrm{a}}$ & Isolate $^{\mathrm{b}}$ & Host, origin, collector ${ }^{\mathrm{c}}$ & TUB $^{\mathrm{d}}$ \\
\hline P. griseorubrum* & CBS 111657 & Human, Maryland, D. Sutton & AY579294 \\
\hline P. hispanicum* & CBS 123910 & V. vinifera, Spain, D. Gramaje & FJ517164 \\
\hline P. hungaricum* & CBS 123036 & V. vinifera, Hungary, B. T. Dula & EU863483 \\
\hline P. inflatipes* & CBS 391.71 & Quercus virginiana, Texas, R. S. Halliwell & $\mathrm{AF} 246805$ \\
\hline P. inflatipes & A $137^{\mathrm{DNA}}$ & V. vinifera, California, S. Rooney-Latham & n.a. \\
\hline P. iranianum* & CBS 101357 & Actinidia chinensis, Italy, F. Calzarano & DQ173097 \\
\hline P. iranianum & DAOM 242361 & V. vinifera, British Columbia, P. Haag \& D. T. O'Gorman & KF764654 \\
\hline P. iranianum & DAOM 242362 & V. vinifera, British Columbia, J. R. Úrbez-Torres & KF764657 \\
\hline P. iranianum & PARC107 & V. vinifera, British Columbia, J. R. Úrbez-Torres & KF764655 \\
\hline P. iranianum & PARC188 & V. vinifera, British Columbia, J. R. Úrbez-Torres & KF764656 \\
\hline P. occidentale* & ICMP 17037 & Vitis sp., New Zealnd, B.S. Weir & EU596524 \\
\hline P. pallidum & CBS 120862 & Prunus armeniaca, South Africa, U. Damm & EU128103 \\
\hline P. prunicola & CBS 120858 & Prunus salicina, South Africa, U. Damm & EU128095 \\
\hline P. roseum* & DAOM 242365 & V. vinifera, British Columbia, J. R. Úrbez-Torres & KF764659 \\
\hline P. roseum & PARC273 & V. vinifera, British Columbia, J. R. Úrbez-Torres & KF764658 \\
\hline P. scolyti* & CBS 113597 & V. vinifera, South Africa, M. Groenewald & AF246800 \\
\hline P. sicilianum* ${ }^{*}$ & CBS 123034 & V. vinifera, Italy, L. Mugnai & EU863488 \\
\hline P. sphinctrophorum & CBS 337.90 & Human, Ontario, S. Krajden \& R. C. Summerbell & DQ173113 \\
\hline P. subulatum* & CBS 113584 & V. vinifera, South Africa, L. Mostert & AY579298 \\
\hline P. tardicrescens & CBS 110573 & Human, Texas, Levi & AY579300 \\
\hline P. theobromatis & CBS 111586 & Theobroma gileri, Ecuador, H. C. Evans & DQ173106 \\
\hline P. tuscanum* $^{*}$ & CBS 123033 & V. vinifera, Italy, L. Mugnai & EU863458 \\
\hline P. venezuelense* & CBS 651.85 & Human, Venzuela, M. B. de Albornoz & AY579320 \\
\hline Phaeomoniella capensis & CBS 123535 & Encephalartos altensteinii, South Africa, A. R. Wood & KR260449 \\
\hline P. chlamydospora* & CBS 117179 & V. vinifera, South Africa, L. Mostert & KF764683 \\
\hline P. chlamydospora & P.ch.9.27DNA & V. vinifera, Spain, M. Tello & n.a. \\
\hline P. chlamydospora & P.ch. $221.0^{\mathrm{DNA}}$ & V. vinifera, Spain, M. Tello & n.a. \\
\hline P. chlamydospora & $\mathrm{UCD} 2548 \mathrm{MO}^{\mathrm{DNA}}$ & Vitis hybrid, Missouri, K. Striegler \& W. D. Gubler & HQ288313 \\
\hline P. chlamydospora & $\mathrm{UCD} 2557 \mathrm{AR}^{\mathrm{DNA}}$ & Vitis hybrid, Arkansas, R. D. Cartwright \& W. D. Gubler & HQ288314 \\
\hline P. chlamydospora & DAOM 242367 & V. vinifera, British Columbia, P. Haag \& D. T. O’Gorman & KF764661 \\
\hline P. chlamydospora & DAOM 242368 & V. vinifera, British Columbia, J. R. Úrbez-Torres & KF764663 \\
\hline P. chlamydospora & PARC13 & V. vinifera, British Columbia, P. Haag \& D. T. O’Gorman & KF764660 \\
\hline P. chlamydospora & PARC34 & $V$. riparia $\times V$. rupestris, British Columbia, P. Haag \& D. T. O'Gorman & $K R 260465$ \\
\hline P. chlamydospora & PARC100 & V. vinifera, British Columbia, J. R. Úrbez-Torres & KF764662 \\
\hline P. chlamydospora & PARC143 & $V$. riparia $\times V$. rupestris, British Columbia, J. R. Úrbez-Torres & KF764664 \\
\hline P. chlamydospora & PARC315 & V. vinifera, British Columbia, J. R. Úrbez-Torres & KF764665 \\
\hline P. chlamydospora & PARC316 & V. vinifera, British Columbia, J. R. Úrbez-Torres & KF764666 \\
\hline P. chlamydospora & PARC326 & V. vinifera, British Columbia, J. R. Úrbez-Torres & KF764667 \\
\hline P. chlamydospora & PARC328 & V. vinifera, British Columbia, J. R. Úrbez-Torres & KF764668 \\
\hline P. dura & CBS 120882 & Prunus salicina, South Africa, U. Damm & $K R 260450$ \\
\hline P. effusa & CBS 120883 & Prunus salicina, South Africa, U. Damm & KR260451 \\
\hline P. pinifoliorum & CBS 114903 & Pinus densiflora, South Korea, H. B. Lee & $K R 260452$ \\
\hline P. prunicola & CBS 120876 & Prunus salicina, South Africa, U. Damm & $K R 260453$ \\
\hline P. tardicola & CBS 121757 & Prunus armeniaca, South Africa, U. Damm & $K R 260454$ \\
\hline P. zymoides & CBS 114904 & Pinus densiflora, South Korea, H. B. Lee & KR260455 \\
\hline Togninia Africana & CBS 120863 & Prunus armeniaca, South Africa, U. Damm & EU128100 \\
\hline T. argentinensis & CBS 777.83 & Soil, Argentina, A. Martínez & DQ173108 \\
\hline T. austroafricana* & CBS 112949 & V. vinifera, South Africa, L. Mostert & DQ173099 \\
\hline T. fraxinopennsylvanica* & CBS 101585 & V. vinifera, California, L. M. Morton \& V. der Water & KF764684 \\
\hline T. fraxinopennsylvanica & DAOM 242363 & V. vinifera, British Columbia, J. R. Úrbez-Torres & KF764669 \\
\hline T. fraxinopennsylvanica & DAOM 242364 & V. vinifera, British Columbia, J. R. Úrbez-Torres & KF764671 \\
\hline T. fraxinopennsylvanica & PARC133 & V. vinifera, British Columbia, J. R. Úrbez-Torres & KF764670 \\
\hline T. fraxinopennsylvanica & PARC143B & $V$. riparia $\times V$. rupestris, British Columbia, J. R. Úrbez-Torres & KF764672 \\
\hline T. griseo-olivacea & CBS 120857 & P. armeniaca, South Africa, U. Damm & EU128097 \\
\hline T. krajdenii* & CBS 110118 & V. vinifera, South Africa, G. van Coller & AY579324 \\
\hline T. minima* & CBS 631.94 & V. vinifera, Italy, L. Mugnai & KF764685 \\
\hline T. minima & $\mathrm{A} 85^{\mathrm{DNA}}$ & V. vinifera, California, S. Rooney-Latham & n.a. \\
\hline T. minima & $\mathrm{UCD} 2546 \mathrm{MO}^{\mathrm{DNA}}$ & Vitis hybrid, Missouri, K. Striegler \& W. D. Gubler & HQ288322 \\
\hline T. minima & $\mathrm{UCD} 2575 \mathrm{AR}^{\mathrm{DNA}}$ & Vitis hybrid, Arkansas, R. D. Cartwright \& W. D. Gubler & HQ288324 \\
\hline T. minima & DAOM 242326 & V. vinifera, British Columbia, J. R. Úrbez-Torres & KF764677 \\
\hline T. minima & DAOM 242360 & V. vinifera, British Columbia, J. R. Úrbez-Torres & KF764679 \\
\hline T. minima & PARC 158 & V. vinifera, British Columbia, J. R. Úrbez-Torres & KF764673 \\
\hline T. minima & PARC172 & V. vinifera, British Columbia, J. R. Úrbez-Torres & KF764674 \\
\hline T. minima & PARC187 & V. vinifera, British Columbia, J. R. Úrbez-Torres & KF764675 \\
\hline T. minima & PARC220 & V. vinifera, British Columbia, J. R. Úrbez-Torres & KF764676 \\
\hline T. minima & PARC324 & V. vinifera, British Columbia, J. R. Úrbez-Torres & KR260448 \\
\hline T. minima & PARC341 & V. vinifera, British Columbia, J. R. Úrbez-Torres & KF764678 \\
\hline T. minima & PARC369 & $V$. riparia $\times V$. rupestris, British Columbia, J. R. Úrbez-Torres & KF764680 \\
\hline T. minima & PARC395 & $V$. berlandieri $\times V$. riparia, British Columbia, J. R. Úrbez-Torres & KF764681 \\
\hline T. novae-zelandiae & CBS 110156 & Cupressus macrocarpa, New Zealand, J. Reid \& S. Reid & DQ173109 \\
\hline T. parasitica* & A $111^{\mathrm{DNA}}$ & V. vinifera, California, S. Rooney-Latham & n.a. \\
\hline T. vibratilis & CBS 117115 & Fagus sylvatica, France, J. Fournier \& G. Corriol & DQ649063 \\
\hline T. viticola* & CBS 101738 & V. vinifera, France, P. Larignon & AF192391 \\
\hline
\end{tabular}


Detection from inoculated soil. The soilborne pathogen I. liriodendri (DAOM 242317 and DAOM 242318) was used in this experiment. For each isolate, five 15-ml Falcon conical centrifuge tubes containing a spore suspension of $10^{6}$ conidia/ml were prepared, as previously described (Petit and Gubler 2005). Five 1-liter pots per fungal isolate were half-filled with double-autoclaved Sunshine Mix 1 potting soil mixture ( 75 to $85 \%$ Canadian Sphagnum peat moss, horticultural-grade perlite, and dolomitic limestone (Sun Gro Horticulture Canada Ltd.) and drench inoculated individually in the center with $15 \mathrm{ml}$ of spore suspension. Five 1-liter pots containing double-autoclaved soil were inoculated with sterile distilled water as negative controls. Soil-inoculated pots were placed in a greenhouse $\left(25 \pm 5^{\circ} \mathrm{C}, 30\right.$ to $40 \%$ relative humidity) for 2 weeks and sterile distilled water was added twice a week to maintain the moisture of the soil. Two weeks after inoculation, $4 \mathrm{~g}$ of soil from the inoculation area was collected from each pot. Soil $(2 \mathrm{~g})$ was put aside for DNA extraction, in which $0.25 \mathrm{~g}$ of soil was used to extract total genomic DNA from each sample using the PowerSoil DNA Isolation Kit (MO BIO Laboratories Inc.,
Carlsbad, CA) following the manufacturer's instructions. The DNA was amplified and the DIG-labeled PCR amplicons hybridized as described before. The other $2 \mathrm{~g}$ of soil were used to attempt the reisolation of I. liriodendri directly from the inoculated soil, as described by Tambong et al. (2006). Soil dilutions were plated on PDA amended with tetracycline hydrochloride $(0.01 \%)$ (PDA-tet) (Sigma-Aldrich) and incubated at $20^{\circ} \mathrm{C}$ in darkness until fungal colonies were observed. Identity of the isolated fungi was confirmed by combining colony and conidia phenotypical characteristics with DNA sequencing using the primers Bt2a and Bt2b (Úrbez-Torres at al. 2014a).

Detection from commercial samples. Fifteen ready-to-plant vines (dormant-rooted grapevines) representing different scion-rootstock combinations and sourced from five different grapevine nurseries (three vines per nursery) were collected from commercial growers in British Columbia in spring 2013. Plants were surface sterilized by submerging them in $4.5 \%$ sodium hypochlorite for $5 \mathrm{~min}$ and washed twice with sterile distilled water. After air drying, a circular wood section of approximately $1 \mathrm{~cm}$ in length from $0.5 \mathrm{~cm}$ above the basal

TABLE 2. List of oligonucleotide probes selected to construct the DNA macroarray

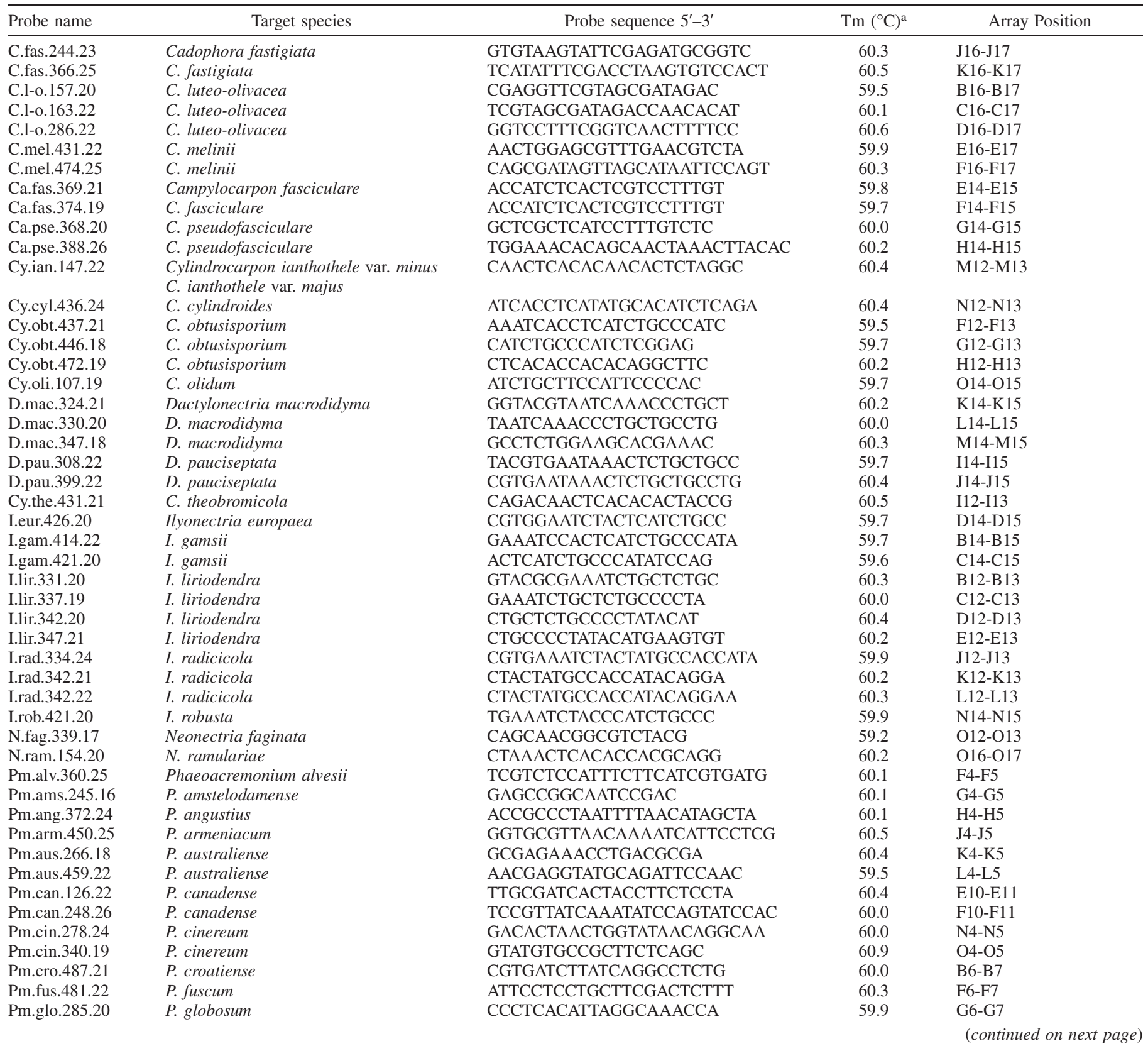

${ }^{a}$ Melting temperature. 
end of the rootstock was collected from each plant and cut in half. One half was sectioned in small pieces using a sterile scalpel and total genomic DNA was extracted, DIG labeled, and hybridized as previously described. The other half was used to attempt the isolation of any YVD fungal pathogen that could reside in the wood tissue (Úrbez-Torres at al. 2014b). Identity of the isolated fungi was confirmed by combining colony and conidia phenotypical characteristics with DNA sequencing using the primers $\mathrm{Bt} 2 \mathrm{a}$ and $\mathrm{Bt} 2 \mathrm{~b}$ (Úrbez-Torres at al. 2014b).

An additional experiment was conducted to evaluate the DNA macroarray by screening 10 scion (5 'Merlot' and 5 Chardonnay) and 15 rootstock (5 each of '3309C', 'SO4', and 'Riparia Gloire') dormant canes collected separately from nursery mother blocks before the grafting and rooting processes. This material was sourced from one nursery. Scion and rootstock materials were surfaced sterilized as described before and circular wood sections of approximately $1 \mathrm{~cm}$ in length were collected from the basal end in both scion and rootstock. Wood pieces were cut in half and processed as described in the previous experiments.

\section{RESULTS}

Sequence analysis. MP trees obtained from each phylogenetic analysis are shown in Supplementary Figures S1 to S4. Both Cadophora and Phaeomoniella isolates showed a high degree of interspecific variation, and no intraspecific variation (0.0) resulted among isolates of $C$. luteo-olivacea and P. chlamydospora, the two main YVD pathogens known from each genus. Similarly, the Campylocarpon, Cylindrocarpon, Dactylonectria, Ilyonectria, and Neonectria isolates included in this study showed high and low degrees of interspecific and intraspecific variation, respectively. However, several exceptions were observed. Isolate Cyl2, identified as I. radicicola (Petit et al. 2011), grouped together with isolates of I. robusta showing no intraspecific variation (0.0). Additionally,

TABLE 2. (continued from preceding page)

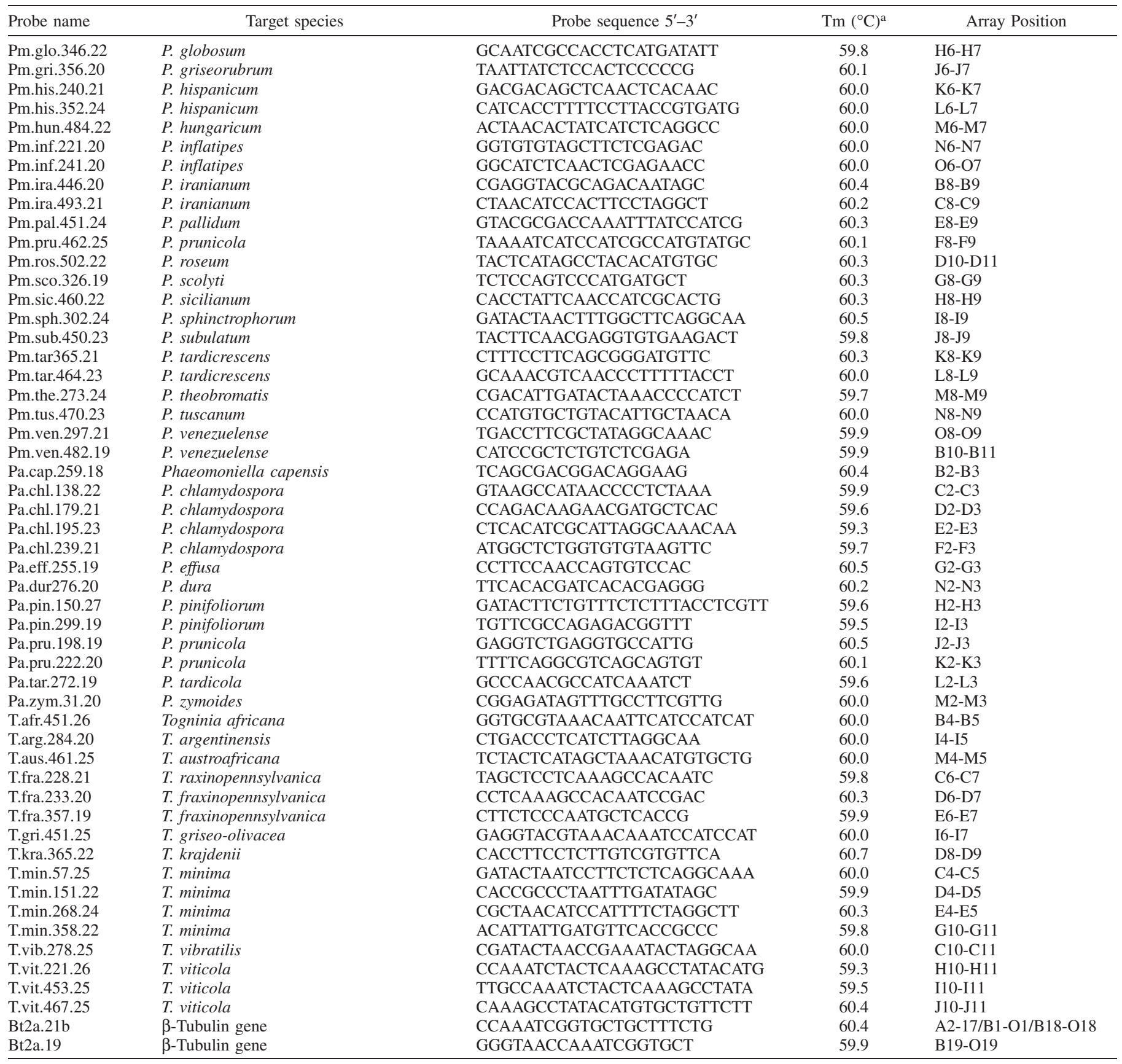


TUB analyses showed a low degree of heterogeneity (0.2) among D. macrodidyma and D. torresensis species. Similarly, Cylindrocarpon ianthothele var. majus isolate CBS 287.92 could not be differentiated from I. europaea isolate CBS 102892 based on TUB sequence analysis and showed a mean interspecific variation of 0.0 . Low intraspecific variation was observed among isolates of T. minima (0.007), Phaeoacremonium iranianum (0.01), and $T$. fraxinopennsylvanica (0.004); and no intraspecific variation (0.0) was observed among isolates of $P$. alvesii, $P$. canadense, $P$. inflatipes, and $P$. roseum. However, very low interspecific variation (0.005) was observed between T. viticola ex-type isolate CBS 101738 and $P$. roseum and, thus, these two species could not be separated based only on TUB sequence analysis.

Oligonucleotide probes design and array construction. The high degree of heterogeneity among species and low variation within isolates of the same species for each of the genera studied was used to design probes capable of detecting and discriminating the different species. In total, 327 probes ( 16 to 26 bases long) were designed using part of the TUB region for the identification of YVD pathogens as well as other nontargeted but phylogenetically closely related species. Six probes were designed as general targets to detect DNA from all fungal species based on the universal primers $\mathrm{Bt} 2 \mathrm{a}$ and $\mathrm{Bt} 2 \mathrm{~b}$ and served as the positive controls. All probes were designed with comparable melting temperatures $\left(60 \pm 1^{\circ} \mathrm{C}\right)$ and were screened by BLAST searches for homology to fungal sequences in GenBank prior to synthesis and incorporation into the array. Four independent arrays that included probes designed to detect and identify Phaeomoniella, Phaeoacremonium-Togninia, Campylocarpon-Dactylonectria-Ilyonectria-CylindrocarponNeonectria, and Cadophora spp. were first constructed and tested against the YVD-targeted pathogens as well as the nontargeted species for each genus. Probes showing either no signal when hybridizing with the corresponding target species or high crosshybridization with nontargeted species were eliminated.

Array specificity. In total, 100 species probes and 2 general probes were selected for the final array (Table 2). To ensure that the selected probes hybridized to the target species but did not crossreact with nontargeted species from all the different genera, the 100 probes were spotted in single membranes and tested against all 138 isolates included in this study for which we had pure cultures or DNA (Table 1). Signal strength was expressed in gray values and varied depending on the isolate-probe combination ranging from 0 (white) to 2,000 (completely black) (Figs. 1 and 2). Positive hybridization signals recorded between each isolate and its homologous probes are shown in Figures 1 and 2. The diagonal line of positive reactions observed confirmed that DIGlabeled PCR amplicons of the different species hybridized as expected, as described by Tambong et al. (2006). Array results' reproducibility was satisfactory because three different DIGlabeled PCR amplicons hybridizations from the same isolate showed the same pattern on separate membranes. In total, 61 taxa, including 34 YVD pathogens, were detected and identified by the array. No species-specific probes could be designed to detect four Cadophora spp. (including Cadophora finlandica, C. gregata, C. hiberna, and C. malorum), a Neonectria sp., T. parasitica (from which we probably did not have a positive isolate), and T. novae-zelandiae.

The final array allowed the detection and discrimination of 15 different species belonging to the genera Campylocarpon, Cylindrocarpon, Dactylonectria, Ilyonectria, and Neonectria, including the black foot pathogens Campylocarpon fasciculare, C. pseudofasciculare, D. macrodidyma, D. pauciseptata, I. europaea, I. liriodendri, and I. robusta (Fig. 1). D. torresensis DIG-labeled PCR amplicons hybridized to two of the three probes designed for D. macrodidyma, D.mac.330.20 and D.mac.347.18. However, a negative reaction of $D$. torresensis isolates to the probe D.mac.324.21 helped to confirm the presence or absence of this species in the array (Fig. 1). DIG-labeled PCR amplicon of isolate Cyl2, previously identified as I. radicicola (Petit et al. 2011), hybridized to $I$. robusta homologous probe I.rob.421.20. This result was consistent with the results obtained from the phylogenetic study, which showed that this isolate is likely to be misidentified. Similarly, isolate Cyl3, originally characterized as Cylindrocarpon sp. (Petit et al. 2011), hybridized to N. ramulariae homologous probe N.ram.154.20. TUB phylogenetic results showed Cyl3 to be closely related to $N$. ramulariae; however, this isolate is likely to be a novel species. DIG-labeled PCR amplicons of the species Cylindrocarpon ianthothele var. minus and $C$. ianthothele var. majus hybridized to the probe Cy.ian.147.22. In this particular case, no other species-specific probe could be designed and, thus, detection but not discrimination between these two species was possible in the final array. Similarly, probe Pa.dur.276.20 hybridized to its homologous species but also to Phaeomoniella chlamydospora isolate CBS 117179. $P$. dura could be differentiated from $P$. chlamydospora because the former DIG-labeled PCR amplicon did not hybridize to any of the Phaeomoniella chlamydospora homologous probes. Four probes were designed for the species Phaeomoniella chlamydospora, one of the most prevalent YVD pathogens worldwide. Among them, probes Pa.chl.179.21, Pa.chl.195.23, and Pa.chl.239.21 performed the best by showing strong hybridization signals and detecting all $P$. chlamydospora isolates included in this study from different geographic origins (Fig. 3). Probes selected for the final array to detect and identify species in the genera Phaeacremonium and Togninia allowed the discrimination of 23 Phaeoacremonium and 6 Togninia spp. (Fig. 2). Additionally, the combination of probes that showed crosshybridization among several Phaeoacremonium and Togninia spp. helped to confirm the presence or absence of five additional taxa (two Phaeoacremonium and three Togninia). For example, Phaeoacremonium cinereum hybridized to its homologous probes but also to the two probes designed to detect $P$. hispanicum. In this case, $P$. cinereum could be differentiated from $P$. hispanicum because the latter DIG-labeled PCR amplicon did not hybridize to $P$. cinereum homologous probes (Fig. 2). Similarly, probe combination assisted in confirming the presence or absence of $P$. roseum, $T$. argentinensis, $T$. fraxinopennsylvanica, and T. viticola in the final array (Fig. 2). Four probes were included to detect T. minima which, along with Phaeomoniella chlamydospora, is the most prevalent Petri disease causal agent. Probe T.min.358.22 was the only one hybridizing with all T. minima isolates included in this study from different countries, while the rest of the probes all hybridized with specific $T$. minima isolates, including CBS 631.94, DAOM 242326, PARC220, PARC369, A84, and UCD2575AR. Interestingly, Phaeoacremonium angustius ex-type DIG-labeled PCR amplicon did not hybridize to its homologous probe Pm.ang.372.24 but cross-hybridized to all four T. minima probes. In contrast, $P$. angustius isolate A155 from California did only hybridize to Pm.ang.372.24 (Fig. 2). These results confirm previous studies that reported $P$. angustius ex-type isolate CBS 249.95 to be contaminated with T. minima (Dupont et al. 2000; Mostert et al. 2006). Therefore, the probes designed in this study to discriminate T. minima are specific for this species. Similarly, isolate A111 from California, originally identified as $T$. parasitica, only hybridized to $T$. minima probe T.min.358.22, which also could indicate a cross contamination or a misidentification. $P$. globosum and $P$. occidentale could both be detected in the final array but not separated (Fig. 2).

Array sensitivity. Phaeomoniella chlamydospora CBS 117179 and T. minima CBS 631.94 DNA serial dilutions were positively detected up to the $10^{-5}$ and $10^{-4}$ dilution, respectively, by single PCR (Fig. 4). In the sensitivity test, homologous probes detected $P$. chlamydospora and T. minima DIG-labeled PCR amplicons up to the $10^{-7}\left(4.2 \times 10^{-6} \mathrm{ng} / \mu \mathrm{l}\right)$ and $10^{-6}\left(7.2 \mathrm{ng} / \mu \mathrm{l} \times 10^{-5}\right)$ dilution, respectively (Fig. 3). All three independent repetitions of the assay for CBS 117179 and CBS 631.94 isolates showed consistent results. The low DNA concentration level detected for both isolates by the DNA array was not visible by agarose gel electrophoresis when performing single PCR. 
Validation of the array against artificially inoculated samples and commercial plant material. Detection from inoculated detached grapevine dormant cuttings. Probes designed to detect and identify T. minina, P. chlamydospora, D. macrodidyma, and I. liriodendri were spotted in duplicates horizontally side by side in the same membrane along with the general probe Bt2a.21b, and multiple membranes were prepared to hybridize with the DIG-label PCR amplicons obtained from each inoculated cane. Thirty-one days after inoculation, vascular discoloration caused by the inoculated fungi on detached Chardonnay dormant canes was observed and recorded (Úrbez-Torres at al. 2014a,b). T. minima, P. chlamydospora, $D$. macrodidyma, and I. liriodendri were positively detected from wood of all artificially inoculated Chardonnay canes (48 total) using the array and showed strong positive signals (Fig. 5). DIG-labeled PCR amplicons from the six canes inoculated with noncolonized agar showed no hybridization with any of the species-specific probes and hybridized with the general Bt2a.21b probe (Fig. 5). T. minima, P. chlamydospora, D. macrodidyma, and I. liriodendri were

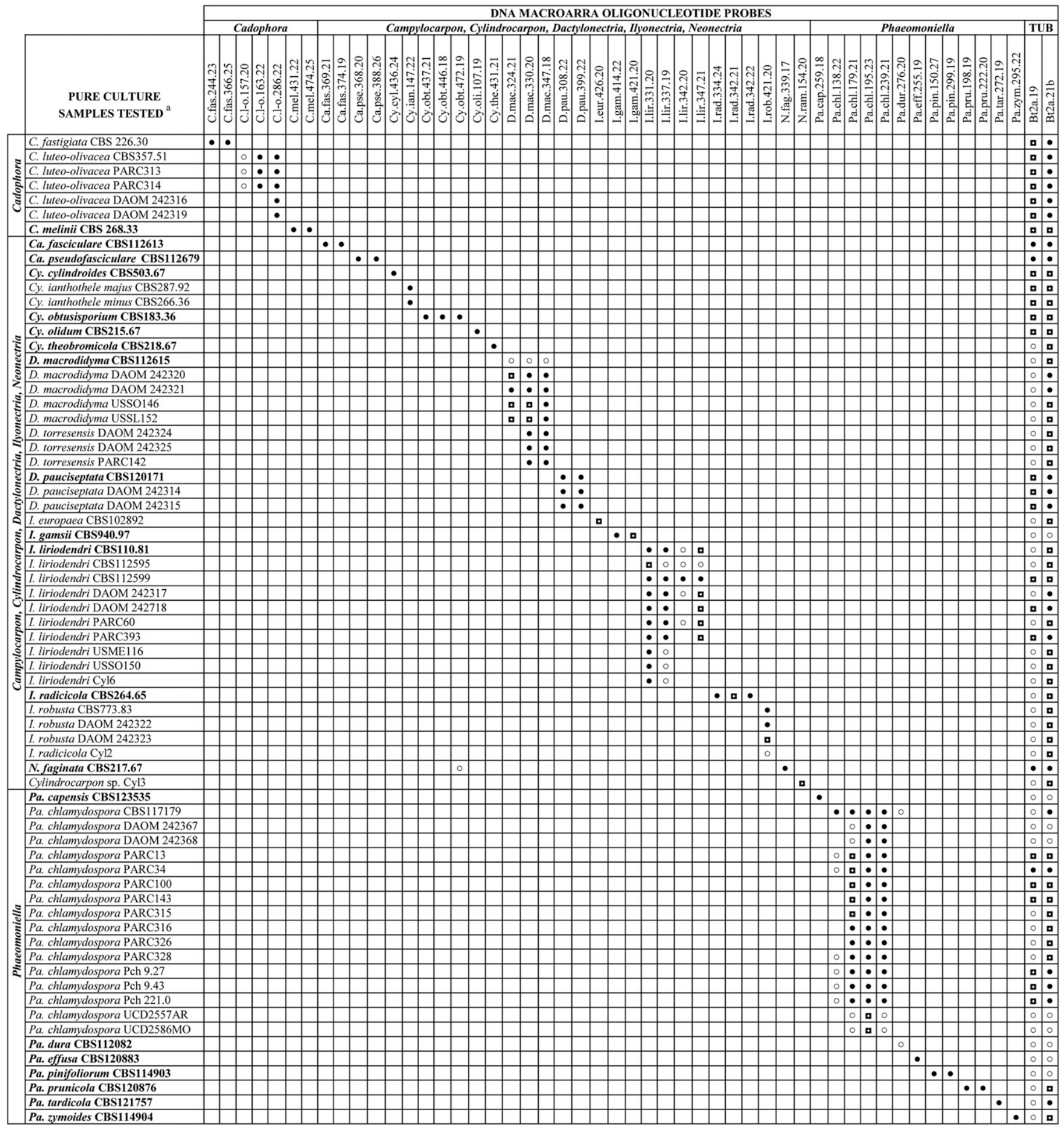

Fig. 1. Specificity of DNA macroarray oligonucleotide probes for targeted young vine decline pathogens in the genera Cadophora, Campylocarpon, Cylindrocarpon, Dactylonectria, Ilyonectria, and Phaeomoniella and other related taxa. Isolates in bold represent ex-type specimens. Grayscale values: No reaction (blank $=0$ to 500$)$, faint reaction $(\bigcirc=501$ to 1,000$)$, medium reaction $(\boldsymbol{Q}=1,001$ to 1,500$)$, and strong reaction $(\bullet=1,501$ to 2,000$)$. 
positively reisolated from 45 of 48 inoculated canes, and fungi obtained from the reisolations were confirmed to be the same as those previously inoculated by combining colony and conidia phenotypical characteristics with DNA sequencing using the primers Bt2a and $\mathrm{Bt} 2 \mathrm{~b}$. No YVD fungi were reisolated from the negative controls.

Soil inoculation. The four probes included in the YVD array for the detection of I. liriodendri positively detected all inoculated soil samples with isolates DAOM 242317 and DAOM 2423182 weeks after inoculation, showing strong hybridization signals (Fig. 5). DIG-labeled PCR amplicons from the five water-inoculated negative controls showed no hybridization with any of the speciesspecific probes and hybridized with the general Bt2a.21b probe (Fig. 5). I. liriodendri isolates DAOM 242317 and DAOM 242318 were detected in all five and four repetitions, respectively, by plating the soil on PDA-tet. Identity of I. liriodendri from colonies growing on PDA-tet was confirmed by combining colony and conidia phenotypical characteristics with DNA sequencing using the primers $\mathrm{Bt} 2 \mathrm{a}$ and $\mathrm{Bt} 2 \mathrm{~b}$. I. liriodendri was not reisolated from the negative controls.

Detection from grapevine commercial plants. Probes included in the final array were spotted on membranes along with the general probe $\mathrm{Bt} 2 \mathrm{a} .21 \mathrm{~b}$ and multiple membranes were prepared to hybridize with the DIG-labeled PCR amplicons obtained from each commercial sample. Probes designed for the detection and identification of YVD fungal pathogens were demonstrated to be specific when tested against ready-to-plant, dormant-rooted commercial plant material. Detailed results on the total number of commercial samples from which YVD pathogens were detected and identified using the array are shown in Table 3. The DNA array confirmed the presence of YVD fungal pathogens in the basal end of the rootstock in 11 of 15 samples tested. YVD pathogens were detected in two of three samples tested from nurseries A, B, C, and D and in all three samples from nursery E. C. luteo-olivacea, $D$. macrodidyma, and T. minima were the most prevalent fungi

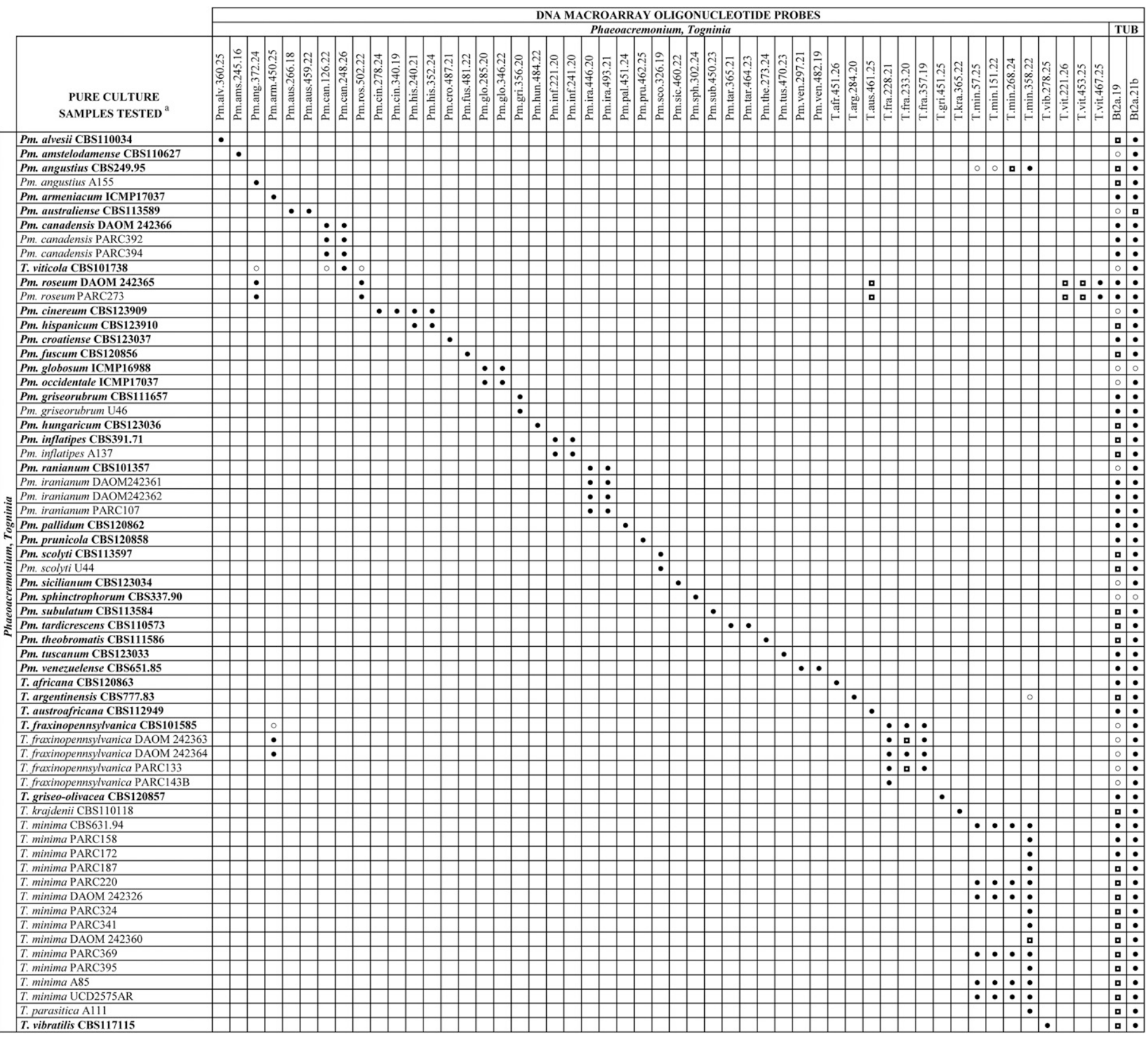

Fig. 2. Specificity of DNA macroarray oligonucleotide probes for targeted young vine decline pathogens in the genera Phaeoacremonium and Togninia and other related taxa. ${ }^{a}$ Isolates in bold represent ex-type specimens. Grayscale values: No reaction (blank $=0$ to 500), faint reaction $(O=501$ to 1,000$)$, medium reaction $(\boldsymbol{Q}=1,001$ to 1,500$)$, and strong reaction $(\mathbf{O}=1,501$ to 2,000$)$. 
detected from six, six, and eight plants, respectively. The other YVD fungal pathogens detected using the DNA array included Campylocarpon fasciculare, Cylindrocarpon obtusisporium, Phaeomoniella chlamydospora, Phaeoacremonium canadense, $P$. croatiense, P. sicilianum, and Cadophora melinii (Table 3). Traditional plating of wood tissue on PDA detected YVD pathogens in 5 of 15 samples. Only two samples (10D and 12D) showed agreement between the results obtained from the wood isolation and those from the DNA array. In the rest of the samples, the traditional plating technique detected fewer YVD species than the DNA array (Table 3).

In the second experiment, the DNA array did not detect any YVD fungi when screening the 10 scion (5 Merlot and 5 Chardonnay) and 15 rootstock (5 of each: 3309C, SO4, and Riparia Gloire) dormant canes collected separately from nursery mother blocks before the grafting and rooting processes. YVD fungi were not isolated from the wood pieces plated on PDA from the different scion and rootstock material.

\section{DISCUSSION}

Development and implementation of integrated pest management strategies require accurate and reliable means of detecting and monitoring plant pathogens (Sholberg et al. 2005). Accordingly, specificity, sensitivity, and robustness are the primary technical requirements that a diagnostic tool for plant pathogens must meet to be validated and commercially used (Lievens and Thomma 2005).

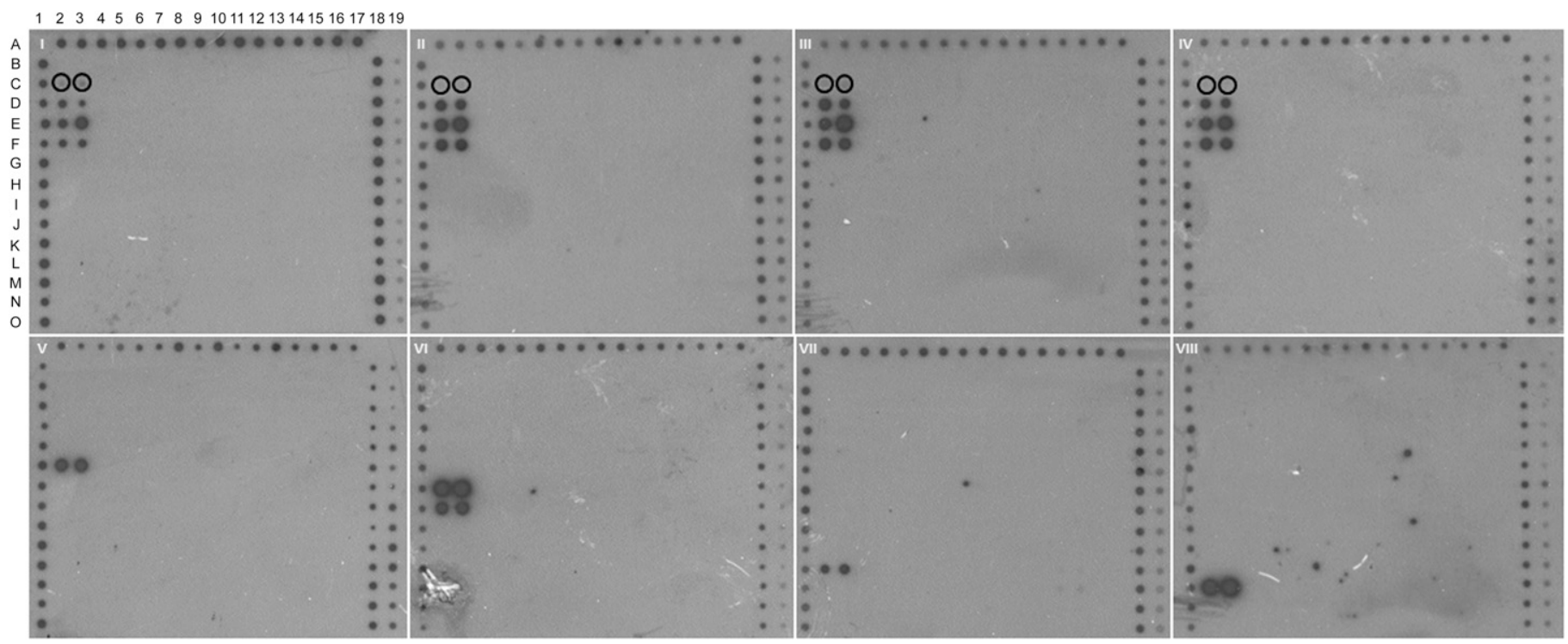

Fig. 3. Detection of Phaeomoniella chlamydospora and other Phaeomoniella spp. DNA from pure culture using the young vine decline DNA macroarray. I to IV, P. chlamydospora $(\mathrm{I}=\mathrm{CBS}$ 117179, II = PARC143, III = Pch221.0, and IV = UCD2557AR); V, P. effusa (CBS 120883); VI, P. pinifoliorum (CBS 114903); VII, P. tardicola (CBS 121757); and VIII, P. zymoides (CBS 114904). Faint reactions are indicated by circles. Oligonucleotide probes: I to IV, C2-C3 (Pa.chl.138.22), D2-D3 (Pa.chl.179.21), E2-E3 (Pa.ch.1195.23), F2-F3 (Pa.chl.239.21). V, G2-G3 (Pa.eff.255.19). VI, H2-H3 (Pa.pin.150.27), I2-I3 (Pa.pin.299.19). VII, L2-L3 (Pa.tar.272.19). VIII, M2-M3 (Pa.zym.31.20).

A Pa. chlamydospora CBS 117179

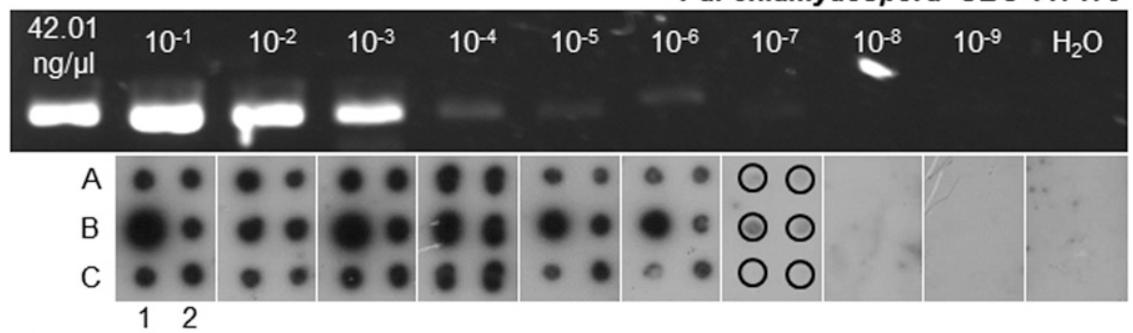

B

T. minima CBS 631.94
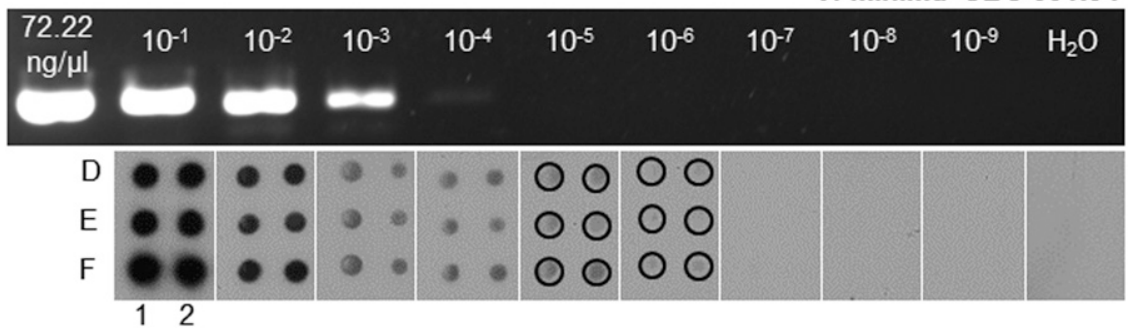

Fig. 4. Sensitivity results of DNA macroarray detection of young vine decline pathogens Phaeomoniella chlamydospora (CBS 117179) and Togninia minima (CBS 631.94). Ethidium bromide-stained agarose gels of $\beta$-tubulin polymerase chain reaction amplicons with starting DNA concentration and ninefold dilutions is shown above membrane results. Oligonucleotide probes included A1-A2 (Pa.chl.179.21), B1-B2 (Pa.chl.195.23), C1-C2 (Pa.chl.239.21), D1-D2 (T.min.151.22), E1-E2 (T.min.268.24), and F1-F2 (T.min.358.22). Faint reactions are indicated by circles. 


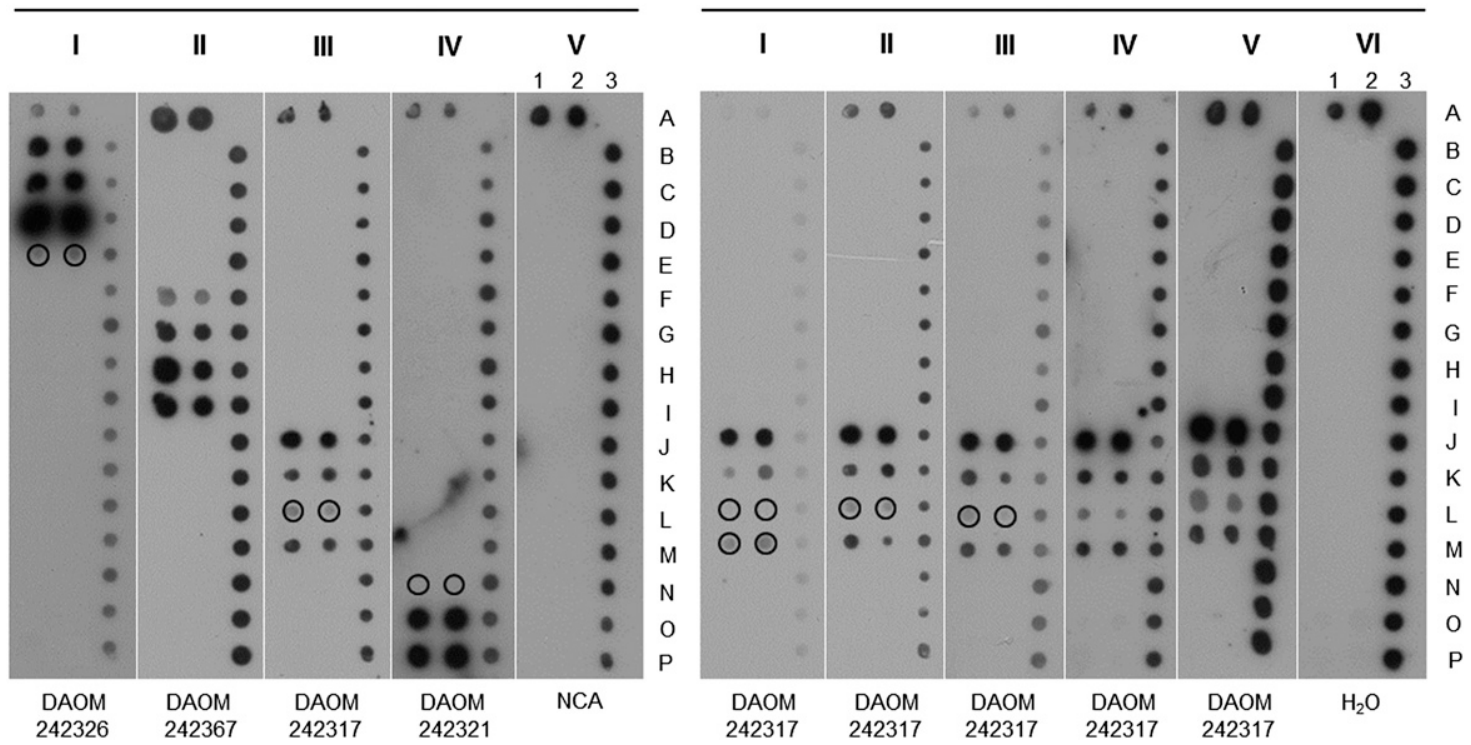

Fig. 5. DNA macroarray detection of young vine decline fungi from artificially inoculated detached dormant canes $(\mathrm{I}=$ Togninia minima, II = Phaeomoniella chlamydospora, $\mathrm{III}=$ Ilyonectria liriodendri, $\mathrm{IV}=$ Dactylonectria macrodidyma, and V = noncolonized agar inoculated control) and artificially inoculated soil (I to $\mathrm{V}=$ I. liriodendra and VI = sterile distilled water inoculated control). Oligonucleotide probes included A1-A2 (Bt2a.21b), B1-B2 (T.min.57.25), C1-C2 (T.min.151.22), D1-D2, (T.min.268.24), E1-E2 (T.min.358.22), F1-F2 (Pa.chl.38.22), G1-G2 (Pa.chl.195.23), H1-H2 (Pa.chl.239.21), I1-I2 (Pa.chl.179.21), J1-J2 (I.lir.331.20), K1-K2 (I.lir.337.19), L1-L2 (I.lir.342.20), M1-M2 (I.lir.347.21), N1-N2 (D.mac.324.21), O1-O2 (D.mac.330.20), P1-P2 (D.mac.347.18), A3 (blank), and B3-P3 (Bt2a.21b). Faint reactions are indicated by circles.

TABLE 3. Detection of young vine decline fungal pathogens at the basal end of the rootstock from commercial ready-to-plant grapevines using the DNA macroarray and the traditional isolation and plating technique ${ }^{\mathrm{a}}$

\begin{tabular}{|c|c|c|c|c|c|}
\hline Sample & Nursery & DIG PCR ${ }^{\mathrm{b}}$ & Species detected ${ }^{c}$ & Direct isolation from wood & Species detected ${ }^{\mathrm{d}}$ \\
\hline 1 & A & + & $\begin{array}{l}\text { Dactylonectria macrodidyma } \\
\text { Phaeoacremonium croatiense }\end{array}$ & - & - \\
\hline 2 & A & - & - & - & - \\
\hline 4 & B & + & $\begin{array}{l}\text { Togninia minima } \\
\text { P. sicilianum } \\
\text { C. luteo-olivacea } \\
\text { Cylindrocarpon obtusisporium } \\
\text { D. macrodidyma }\end{array}$ & - & - \\
\hline 5 & B & + & $\begin{array}{l}\text { Campylocarpon fasciculare } \\
\text { D. macrodidyma }\end{array}$ & - & - \\
\hline 6 & B & - & - & - & - \\
\hline 7 & $\mathrm{C}$ & - & - & - & - \\
\hline 8 & $\mathrm{C}$ & + & T. minima & - & - \\
\hline 9 & $\mathrm{C}$ & + & $\begin{array}{l}\text { T. minima } \\
\text { Cadophora luteo-olivacea } \\
\text { D. macrodidyma }\end{array}$ & - & - \\
\hline 13 & $\mathrm{E}$ & + & $\begin{array}{l}\text { P. chlamydospora } \\
\text { T. minima } \\
\text { C. luteo-olivacea } \\
\text { D. macrodidyma }\end{array}$ & - & - \\
\hline 14 & $\mathrm{E}$ & + & $\begin{array}{l}\text { T. minima } \\
\text { Phaeoacremonium canadense } \\
\text { C. melinii }\end{array}$ & + & T. minima \\
\hline 15 & $\mathrm{E}$ & + & $\begin{array}{l}\text { Phaeomoniella chlamydospora } \\
\text { T. minima } \\
\text { C. luteo-olivacea }\end{array}$ & + & $\begin{array}{l}\text { P. chlamydospora } \\
\text { T. minima }\end{array}$ \\
\hline
\end{tabular}

a Symbols: + and - indicate positive and negative detection, respectively.

b Digoxigenin (DIG)-labeled polymerase chain reaction (PCR) plus hybridization.

c Species identification based on the YVD-DNA macroarray.

d Species identification based on colony and conidia morphological characteristics and DNA sequencing. 
The specificity of DNA macroarray technology has long been demonstrated. Thus, the ability of this technique to precisely detect plant-pathogenic bacteria, fungi, oomycetes, and viruses, including those from complex taxonomical groups, is well documented (Fessehaie et al. 2003; Lévesque et al. 1998; Sholberg et al. 2005; Thompson et al. 2012). The DNA macroarray developed in this study shows, for the first time, the accurate detection of 61 different fungal species, including 37 taxa associated with the decline of young vines, which further supports the specificity of this technique when applied to detect and discriminate among a large group of pathogens. Molecular identification of YVD pathogens has long been based on targeting the conserved internal transcribed spacer (ITS) region ITS1-5.8S-ITS2. However, the sequence variation within this region has been proved deficient to discriminate among all described YVD fungal taxa; and thus, other genes such as TUB, actin, translation elongation factor $1-\alpha$ (TEF-1 $\alpha$ ), and histone 3 (H3) need to be currently used in multigene phylogenetic studies to correctly identify YVD fungi (Cabral et al. 2012a,b; Mostert et al. 2006; Úrbez-Torres et al. 2014a,b). The DNA macroarray developed in this study showed a high degree of specificity to discriminate among YVD fungi by targeting only part of the TUB gene, which can significantly minimize time and cost of having to sequence several loci and conduct complex and time-consuming phylogenetic studies for identification purposes only. The principle behind the DNA macroarray is based on the detection of singlenucleotide polymorphisms among species, which was shown to be a potential problem when trying to cover the range of variation sometimes existing within species (Lévesque et al. 1998). This study shows that a single base mismatch in the TUB region is sufficient to design species-specific oligonucleotide probes to detect and identify a broad range of different YVD fungal pathogens, including those phylogenetically very closely related. Additionally, specificity of this macroarray system and the oligonucleotide probes designed are further demonstrated by successfully testing them against same species' isolates from different hosts and continents. On the other hand, 8 of the 72 species included in this study could not be detected by designing probes in the TUB region and 4 other species were detected but could not be discriminated (C. ianthothele var. minus from $C$. ianthothele var. majus and Phaeoacremonium globosum from $P$. occidentale). Recent studies have revealed that, by adding the TEF- $1 \alpha$ and $\mathrm{H} 3$ genes in multigene phylogenetic studies for the two most common black foot pathogens (D. macrodidyma (Halleen, Schroers \& Crous) L. Lombard, van der Merwe \& J. Z. Groenew. \& Crous and I. radicicola (Gerlach \& L. Nilsson) P. Chaverri \& C. Salgado) they actually comprise cryptic species that collectively contain at least 20 new species (Cabral et al. 2012b). A combination of multiple gene regions that contain alternating areas of high conservation and high variability can substantially enhance the specificity of any diagnostic assay (Lievens and Thomma 2005). Recently, Chen at al. (2013) significantly improved both speciesand genus-wide diagnosis for the pathogen Phytophthora de Bary by developing a DNA macroarray using multiple markers, including ITS, cox 1 , and cox2-1 spacer. Accordingly, combining the TUB region with any other conserved but still informative regions used for YVD fungi identification could enhance the specificity of the current DNA macroarray and would allow the detection and identification of a greater number of species, including those cryptic species otherwise unidentifiable based on phenotypical characteristics and single-gene sequencing.

Detection of pathogens before plants are infected or symptoms have developed, the latter being critical in regulatory aspects of quarantine organisms, requires highly sensitive detection tools because pathogen inoculum at that stage can be extremely low (Lievens and Thomma 2005). Currently, most of these detection tools are PCR based and, to some extent, immunological assays are also used. Previous studies reported detection thresholds for Phaeomoniella chlamydospora of less than $1 \mathrm{pg}$ using species-specific primers in single PCR (Ridgway et al. 2002), lowered to $1 \mathrm{fg}$ when nested PCR was used (Retief et al. 2006). Moreover, Martín et al. (2012) were able to detect as little as $50 \mathrm{fg}$ of DNA of T. minima by using species-specific primers in real-time PCR. Similarly, Agustí-Brisach et al. (2014) detected a DNA concentration of Ilyonectria spp. as low as $0.004 \mathrm{pg} / \mu \mathrm{l}$ from soil or plants using realtime PCR. Lievens et al. (2005) showed that less than $0.5 \mathrm{pg}$ of DNA from a single target organism could easily be detected by selecting the appropriate oligonucleotide detector sequence at the right concentration in a macroarray system. Detection limits of the DNA macroarray developed in this study using single PCR were established to be 42 and 72 fg DNA for $P$. chlamydospora and T. minima, respectively. These results agree with those reported by Lievens et al. (2005) and are similar to those obtained by Martos et al. (2011), in which 87 fg of DNA of $P$. chlamydospora was positively detected using cooperational PCR coupled with dot-blot hybridization. Similarly, Sholberg et al. (2005) detected the equivalent genomic DNA of two spores of the cherry powdery mildew pathogen Podosphaera leucotricha (Ellis \& Everh.) E. S. Salmon using single PCR with a DNA macroarray. Following the same technique, Zhang et al. (2008) established the detection limit for the fungal pathogens Stemphylium solani G. F. Weber and Fusarium sambucinum Fuckel at $40 \mathrm{fg}$ of DNA. Detection limits shown by DNA macroarrays, including ours, are comparable with, if not lower than, those obtained by single, nested, or real-time PCR, with the multiplexing advantage that the DNA macroarray technique possesses. Therefore, results from the current study add to previous ones in supporting the potential that DNA macroarray technology has as an alternative detection and diagnostic tool to the current PCR methods used.

Though specificity, sensitivity, and reproducibility are the main pillars of a reliable diagnostic and detection tool, multiplexing and pathogen quantification are currently becoming a "must-have" on diagnostic assays (Lievens and Thomma 2005). Most of the molecular assays currently used to detect and diagnose YVD fungi only target one specific pathogen, primarily Phaeomoniella chlamydospora or T. minima (Groenewald et al. 2000; Martín et al. 2012; Martos et al. 2011; Ridgway et al. 2002; Tegli et al. 2000). To date, over 50 different fungi belonging to ten different genera are known to be associated with YVD. Furthermore, it has been shown that a single grapevine can be infected by numerous YVD fungi creating a disease complex (Úrbez-Torres 2014a,b), which is a situation not particular to grape but commonly observed in many other annual and perennial crops. Accordingly, molecular assays capable of detecting multiple pathogens simultaneously are required. With regard to the YVD pathosystem, few studies have been undertaken to accomplish this task. Aroca and Raposo (2007) developed a PCRbased strategy by using genus-specific primers along with restriction enzyme digestion that allowed the simultaneous detection and discrimination of seven different species of Phaeoacremonium. Later, Alániz et al. (2009) developed a multiplex PCR system for the detection of three black foot pathogens: D. macrodidyma, D. pauciseptata, and I. liriodendri. Though these studies were the first to develop a simultaneous detection assay for YVD fungi, they were only able to detect a very limited number of species at a time. Alternatively, the DNA macroarray developed in this study has the capability to simultaneously detect and discriminate 61 different fungal species, including 37 taxa associated with YVD. With such a wide range of taxonomically unrelated fungal pathogens causing YVD, the multiplexing capacity shown by the current DNA macroarray is the most significant advantage and contribution when comparing it with the currently available PCR-based detection assays. Moreover, the DNA array technology was originally designed to detect an unlimited number of microorganisms and, thus, allow the inclusion of new species- or genus-specific oligonucleotide probes to the system, which is a significant consideration because YVD novel species are being described yearly. 
In contrast, two main disadvantages can be described for the current DNA macroarray: the lack of pathogen quantification and the impossibility of determining whether the DNA detected corresponds to a live or death organism. Whereas the latter disadvantage is commonly associated with almost all DNA-based detection methods, the former is an important aspect when determining minimum pathogen thresholds that could lead to disease development and, subsequently, possible economic losses. Realtime PCR is currently the most widely used technique to precisely quantify not only YVD fungi (Agustí-Brisach et al. 2014; Martín et al. 2012) but also all other pathogens. However, the detriment of this technique is that it cannot quantify more than a few different species in a single assay. Alternatively, several studies have shown the possibility of implementing a quantitative aspect into a DNA macroarray. For instance, Lievens et al. (2005) established a strong correlation between hybridization signals and pathogen DNA concentration for the economically important vascular pathogens Verticillium albo-atrum Reinke \& Berthold and V. dahliae Kleb. Additionally, this study showed a high degree of correlation between quantitative assessments of several tomato pathogens performed using DNA array technology and real-time PCR. Similarly, in a DNA macroarray developed to detect and monitor the most economically important apple diseases, Sholberg et al. (2005) successfully produced a standard series of grayscale values that correlated with known concentrations of Podosphaera leucotricha conidia and also included quantification studies for the apple pathogen Erwinia amylovora (Burrill 1882) Winslow et al. Based on the success of the aforementioned studies, work is currently underway at the Pacific Agri-Food Research Centre Plant Pathology Laboratory to implement a quantitative aspect into the YVD DNA macroarray which, if successful, could be applied in many different types of research; including, for example, epidemiological studies for the detection, discrimination, and quantification of YVD fungi from environmental samples.

Identification of YVD fungi has primarily been based on morphological characteristics after traditional methods of isolation and culturing. However, this has resulted in constant misidentifications because discrimination among YVD fungi based solely on morphology is extremely challenging due to phenotypical plasticity among species, overlapping in the morphology of microscopic structures, and presence of cryptic species. Furthermore, YVD fungi in the genera Phaeomoniella, Phaeoacremonium, Togninia, and Cadophora are characterized as slow growing, taking up to 3 weeks to grow on enriched medium. This does not only delay any diagnostic result but also makes it extremely difficult to detect these fungi when isolation and culturing is conducted, because they can be easily overgrown by other microorganisms (Aroca and Raposo 2007). Though molecular techniques are currently available to identify YVD fungi, they are primarily based on DNA sequencing obtained from pure cultures. Accordingly, high isolation and fungal taxonomic skills are still required to isolate these pathogens from symptomatic wood and identify them at a very early growth stage, before contamination occurs by faster-growing fungi. The YVD DNA macroarray developed in this study was successfully validated against not only pure cultures and artificially inoculated plant and soil material but also commercial samples. The DNA macroarray proved to be highly specific and sensitive in detecting and identifying nine different YVD pathogens from 11 of the 15 commercial plants tested. In contrast, traditional isolation was only able to detect three YVD species in 5 of the 15 plants. Moreover, the DNA macroarray allowed the detection of Cadophora melinii, Campylocarpon fasciculare, Cylindrocarpon obtusisporium, Phaeoacremonium croatiense, and $P$. sicilianum, all YVD fungi not known to occur in Canada. This DNA macroarray showed not only greater sensitivity than the traditional culturing method but also a significant reduction in time. Although identification of YVD fungi by traditional methods from the commercial samples took up to 6 weeks (this included symptomatic tissue culture, fungal isolation, morphological fungal identification, obtaining pure fungal colonies, DNA extraction, PCR amplification, and sequencing), results using the DNA macroarray were obtained within $72 \mathrm{~h}$. These results highlight the greater sensitivity offered by this technique as opposed to traditional culturing methods and are in concordance with those published by Aroca and Raposo (2007), who demonstrated that a nested PCR method was capable of detecting Phaeoacremonium spp. in twice the number of samples in a much shorter period of time when compared with traditional culturing.

Studies conducted on YVD during the last decade have undoubtedly concluded that planting material used in the establishment of new vineyards can already be infected with these fungi, either from contaminated material collected in the nursery mother blocks or by infection at different steps during the grapevine propagation process in the nursery (Gramaje and Armengol 2011). Furthermore, it is also well known that several YVD fungi can be detected from symptomless grapevines in the nursery and in the field (González and Tello 2011; Halleen et al. 2003; Stamp 2001). Therefore, it has been hypothesized that these fungi could also behave as latent pathogens until an abiotic (water or nutrient deficit, frost, or poor planting conditions) or biotic (nematodes, diseases, and pests) stress triggers the pathogenic phase of these fungi (Ferreira et al. 1999; Gramaje and Armengol 2011; Stamp 2001). Accordingly, highly sensitive tools that can detect low pathogen inoculum levels have urgently been demanded by the grapevine nursery industry to effectively identify potential sources of infection and to assess the health status of the propagated material before leaving the nursery. The DNA macroarray developed in this study shows great potential as a detection and screening tool for YVD fungi to be used in commercial operations offering high sensitivity, high throughput, and multiplexing capability, with minimal taxonomic expertise and much shorter diagnosis time. Though specificity, sensitivity, robustness, multiplexing, and quantification have been discussed here to be the primary technical requirements for any diagnostic tool, including DNA macroarray systems, final cost should not be ignored because it is probably the most critical factor in accepting and commercializing a detection tool. Therefore, further studies are needed to determine the increase that the adaptation of this DNA macroarray system into the grapevine propagation process will have on the final cost per plant. Studies are currently being conducted in our laboratory to determine the conditions of the grapevine-propagated material being planted in British Columbia with regard of YVD pathogens and to evaluate the potential use of the YVD DNA macroarray as a standard detection tool by the nursery industry as well as by public or private diagnostic laboratories. In addition, work is underway to expand the DNA macroarray and include fungal pathogens associated with the rest of GTD, including Botryosphaeria, Eutypa, and Phomopsis dieback.

\section{ACKNOWLEDGMENTS}

This study was made possible through a research grant awarded by the British Columbia Wine Grape Council and with matching funds provided by Agriculture and Agri-Food Canada's Developing Innovative AgriProducts program. We thank M. Tello (Instituto Madrileño de Investigación y Desarrollo Rural, Agrario y Alimentario, IMIDRA, Alcalá de Henares, Spain), P. Rolshausen (Department of Botany and Plant Sciences, University of California-Riverside), and W. D. Gubler (Plant Pathology Department, University of California-Davis) for providing DNA samples; and J. Dick (University of British Columbia, Vancouver, BC, Canada) and M. Sheepwash (Vancouver Island University, Nanaimo, BC, Canada) for their valuable technical assistance in this study.

\section{LITERATURE CITED}

Agustí-Brisach, C., and Armengol, J. 2013. Black-foot disease of grapevine: An update on taxonomy, epidemiology and management strategies. Phytopathol. Mediterr. 52:245-261. 
Agustí-Brisach, C., Mostert, L., and Armengol, J. 2014. Detection and quantification of Ilyonectria spp. associated with black-foot disease of grapevine in nursery soils using multiplex, nested PCR and real-time PCR. Plant Pathol. 63:316-322.

Alániz, S., Armengol, J., García-Jimenez, J., Abad-Campos, P., and León, M. 2009. A multiplex PCR system for the specific detection of Cylindrocarpon liriodendri, C. macrodidymum, and C. pauciseptatum from grapevine. Plant Dis. 93:821-825.

Aroca, A., and Raposo, R. 2007. PCR-based strategy to detect and identify species of Phaeoacremonium causing grapevine disease. Appl. Environ. Microbiol. 73:2911-2918.

Cabral, A., Groenewald, Z. J., Rego, C., Oliveira, H., and Crous, P. W. 2012a. Cylindrocarpon root rot: Multi-gene analysis reveals novel species within the Ilyonectria radicicola species complex. Mycol. Prog. 11:655-688.

Cabral, A., Rego, C., Nascimento, T., Oliveira, H., Groenewald, Z., and Crous, P. W. 2012b. Multi-gene analysis and morphology reveal novel Ilyonectria species associated with black foot disease of grapevines. Fungal Biol. 116:62-80.

Call, D. R., Brockman, F. J., and Chandler, D. P. 2001. Detecting and genotyping Escherichia coli O157:H7 using multiplex PCR and nucleic acid microarray. Int. J. Food Microbiol. 67:71-80.

Chen, W., Robleh Djama, Z., Coffey, M. D., Martin, F. N., Bilodeau, G. J., Radmer, L., Denton, G., and Lévesque, C. A. 2013. Membrane-based oligonucleotide array developed from multiple markers for the detection of many Phytophthora species. Phytopathology 103:43-54.

Crous, P. W., and Gams, W. 2000. Phaeomoniella chlamydospora gen. et comb. nov., a causal organism of Petri grapevine decline and esca. Phytopathol. Mediterr. 39:112-118.

Crous, P. W., Gams, W., Wingfield, M. J., and van Wyk, P. S. 1996. Phaeoacremonium gen. nov. associated with wilt and decline diseases of woody hosts and human infections. Mycologia 88:786-796.

Dupont, J., Laloui, W., Magnin, S., Larignon, P., and Roquebert, M.-F. 2000. Phaeoacremonium viticola, a new species associated with esca disease of grapevine in France. Mycologia 92:499-504.

Eskalen, A., Feliciano, A. J., and Gubler, W. D. 2007. Susceptibility of grapevine pruning wounds and symptom development in response to infection by Phaeoacremonium aleophilum and Phaeomoniella chlamydospora. Plant Dis. 91:1100-1104.

Ferreira, J. H. S., Van Wyk, P. S., and Calitz, F. J. 1999. Slow dieback of grapevine in South Africa: Stress-related predisposition of young vines for infection by Phaeoacremonium chlamydosporum. S. Afr. J. Enol. Vitic. 20:43-46.

Fessehaie, A., De Boer, S. H., and Lévesque, C. A. 2003. An oligonucleotide array for the identification and differentiation of bacteria pathogenic on potato. Phytopathology 93:262-269.

Fleurat-Lessard, P., Luini, E., Berjeaud, J.-M., and Roblin, G. 2010. Diagnosis of grapevine esca disease by immunological detection of Phaeomoniella chlamydospora. Aust. J. Grape Wine Res. 16:455-463.

Fleurat-Lessard, P., Luini, E., Berjeaud, J.-M., and Roblin, G. 2014. Immunological detection of Phaeoacremonium aleophilum, a fungal pathogen found in esca disease. Eur. J. Plant Pathol. 139:137-150.

Gimenez-Jaime, A., Aroca, A., Raposo, R., García-Jimenez, J., and Armengol, J. 2006. Occurrence of fungal pathogens associated with grapevine nurseries in Spain. J. Phytopathol. 154:598-602.

Glass, N. L., and Donaldson, G. 1995. Development of primer sets designed for use with PCR to amplify conserved genes from filamentous Ascomycetes. Appl. Environ. Microbiol. 61:1323-1330.

González, V., and Tello, M. L. 2011. The endophytic mycota associated with Vitis vinifera in central Spain. Fungal Divers. 47:29-42.

Gramaje, D., and Armengol, J. 2011. Fungal trunk pathogens in the grapevine propagation process: Potential inoculum sources, detection, identification, and management strategies. Plant Dis. 95:1040-1055.

Gramaje, D., Armengol, J., Mohammadi, H., Banihashemi, Z., and Mostert, L. 2009. Novel Phaeoacremonium species associated with petri disease and esca of grapevine in Iran and Spain. Mycologia 101:920-929.

Gramaje, D., Mostert, L., and Armengol, J. 2011. Characterization of Cadophora luteo-olivacea and C. melinii isolates obtained from grapevines and environmental samples from grapevine nurseries in Spain. Phytopathol. Mediterr. 50:S112-S116.

Groenewald, M., Bellstedt, D. U., and Crous, P. U. 2000. A PCR-based method for the detection of Phaeomoniella chlamydospora in grapevines. S. Afr. J. Sci. 96:43-46.

Hall, T. A. 1999. BioEdit: A user-friendly biological sequence alignment editor and analysis program for Windows 95/98/NT. Nucleic Acid S. 41:95-98.

Halleen, F., Crous, P. W., and Petrini, O. 2003. Fungi associated with healthy grapevine cuttings in nurseries, with special reference to pathogens involved in the decline of young vines. Australas. Plant Pathol. 32:47-52.

Halleen, F., Schroers, H. J., Groenewald, J. Z., and Crous, P. W. 2004. Novel species of Cylindrocarpon (Neonectria) and Campylocarpon gen. nov. associated with black foot disease of grapevines (Vitis spp.). Stud. Mycol. 50: 431-455.
Hofstetter, V., Buyck, V., Croll, D., Viret, O., Couloux, A., and Gindro, K. 2012. What if esca disease of grapevine were not a fungal disease? Fungal Divers. 54:51-67.

Kawasaki, E., Saiki, R., and Erlich, H. 1993. Genetic-analysis using polymerase chain reaction-amplified DNA and immobilized oligonucleotide probes-reverse dot-blot typing. Methods Enzymol. 218:369-381.

Lévesque, C. A., Harlton, C. E., and de Cook, A. W. A. M. 1998. Identification of some oomycetes by reverse dot blot hybridization. Phytopathology 88: 213-222.

Lievens, B., Brouwer, M., Vanachter, A. C. R. C., Lévesque, C. A., Cammue, B. P. A., and Thoma, B. P. H. J. 2003. Design and development of a DNA array for rapid detection and identification of multiple tomato vascular wilt pathogens. FEMS Microbiol. Lett. 223:113-122.

Lievens, B., Brouwer, M., Vanachter, A. C. R. C., Lévesque, C. A., Cammue, B. P. A., and Thomma, B. P. H. J. 2005. Quantitative assessment of phytopathogenic fungi in various substrates using a DNA macroarray. Environ. Microbiol. 7:1698-1710.

Lievens, B., and Thomma, B. P. H. J. 2005. Recent developments in pathogen detection arrays: Implications for fungal plant pathogens and use in practice. Phytopathology 95:1374-1380.

Lombard, L., Van Der Merwe, N. A., Groenewald, J. Z., and Crous, P. W. 2014. Lineages in Nectriaceae: Re-evaluating the generic status of Ilyonectria and allied genera. Phytopathol. Mediterr. 53:515-532.

Maluta, D. R., and Larignon, P. 1991. Pied-noir: Mieux vaut prevenir. Viti 11: 71-72.

Maoka, T., Sugiyama, S., Maruta, Y., and Hataya, T. 2010. Application of CDNA macroarray for simultaneous detection of 12 potato viruses. Plant Dis. 94:1248-1254.

Martín, M. T., Cobos, R., Martín, L., and López-Enríquez, L. 2012. Rela-Time PCR detection of Phaeomoniella chlamydospora and Phaeoacremonium aleophilum. Appl. Environ. Microbiol. 78:3985-3991.

Martos, S., Torres, E., Abdessamad El Bakali, M., Raposo, R., Gramaje, D., Armengol, J., and Luque, J. 2011. Co-operational PCR coupled with dot blot hybridization for the detection of Phaeomoniella chlamydospora on infected grapevine wood. J. Phytopathol. 159:247-254.

Minutillo, S. A., Mascia, T., and Galitelli, D. 2012. A DNA probe mix for the multiplex detection of ten artichoke viruses. Eur. J. Plant Pathol. 134: 459-465.

Mostert, L., Groenewald, J. Z., Summerbell, R. C., Gams, W., and Crous, P. W. 2006. Taxonomy and pathology of Togninia (Diaporthales) and its Phaeoacremonium anamorphs. Stud. Mycol. 54:1-113.

Overton, B. E., Steward, E. L., Qu, X., Wenner, N. G., and Christ, B. J. 2004. Qualitative real-time PCR-SYBR ${ }^{\circledR}$ Green detection of Petri disease fungi. Phytopathol. Mediterr. 43:403-410.

Owens, C. B., and Szalanskij, A. L. 2005. Filter paper for preservation, storage, and distribution of insect and pathogen DNA samples. Med. Entomol. 42:709-711.

Pascoe, I., and Cottral, E. 2000. Developments in grapevine trunk diseases research in Australia. Phytopathol. Mediterr. 39:68-75.

Petit, E., Barriault, E., Baumgartner, K., Wilcox, W., and Rolshausen, P. E. 2011. Cylindrocarpon species associated with black-foot of grapevine in northeastern United States and southeastern Canada. Am. J. Enol. Vitic. 62: $177-183$.

Petit, E., and Gubler, W. D. 2005. Characterization of Cylindrocarpon species, the cause of black foot disease of grapevines in California. Plant Dis. 89: 1051-1059.

Retief, E., McLeod, A., and Fouirie, P. H. 2006. Potential Inoculum Sources of Phaeomoniella chlamydospora in South African Grapevine Nurseries. Eur. J. Plant Pathol. 115:331-339.

Ridgway, H. J., Sleight, B. E., and Stewart, A. 2002. Molecular evidence for the presence of Phaeomoniella chlamydospora in New Zealand nurseries, and its detection in rootstock mothervines using species-specific PCR. Australas. Plant Pathol. 31:267-271.

Saiki, R. K., Walsh, P. S., Levenson, C. H., and Elrich, H. A. 1989. Geneticanalysis of amplified DNA with immobilized sequence-specific oligonucleotide probes. Proc. Natl. Acad. Sci. USA 86:6230-6234.

Scheck, H. J., Vasquez, S. J., Fogle, D., and Gubler, W. D. 1998. Grape growers report losses to black-foot and grapevine decline. Calif. Agric. 52:19-23.

Sholberg, P., O'Gorman, D., Bedford, K., and Lévesque, C. A. 2005. Development of a DNA macroarray for detection and monitoring of economically important apple diseases. Plant Dis. 89:1143-1150.

Sidoti, A., Buonocore, E., Serges, T., and Mugnai, L. 2000. Decline of young grapevines associated with Phaeoacremonium chlamydosporum in Sicily (Italy). Phytopathol. Mediterr. 39:87-91.

Stamp, J. A. 2001. The contribution of imperfections in nursery stock to the decline of young vines in California. Phytopathol. Mediterr. 40:369-375.

Tambong, J. T., de Cook, A. W. A. M., Tinker, N. A., and Lévesque, C. A. 2006. Oligonucleotide array for identification and detection of Pythium species. Appl. Environ. Microbiol. 72:2691-2706. 
Tamura, K., Peterson, D., Peterson, N., Stecher, G., Nei, M., and Kumar, S. 2011. MEGA5: Molecular evolutionary genetics analysis using maximum likelihood, evolutionary distance, and maximum parsimony methods. Mol. Biol. Evol. 28:2731-2739.

Tegli, S., Bertelli, E., and Surico, G. 2000. Sequence analysis of ITS ribosomal DNA in five Phaeoacremonium species and development of a PCR-based assay for the detection of Phaeoacremonium chlamydosporum and Phaeoacremonium aleophilum in grapevine tissue. Phytopathol. Mediterr. 39:134-149.

Thompson, J. R., Fuchs, M., Fisher, K. F., and Perry, K. L. 2012. Macroarray detection of grapevine leafroll-associated viruses. J. Virol. Methods 183:161-169.

Travadon, R., Lawrence, D. P., Rooney-Latham, S., Gubler, W. D., Wilcox, W. F., Rolshausen, P. E., and Baumgartner, K. 2015. Cadophora species associated with wood-decay of grapevine in North America. Fungal Biol. 119:53-66.

Úrbez-Torres, J. R., Haag, P., Bowen, P., and O'Gorman, D. T. 2014a. Grapevine Trunk Diseases in British Columbia: Incidence and characterization of the fungal pathogens associated with black foot disease of grapevine. Plant Dis. 98:456-468.

Úrbez-Torres, J. R., Haag, P., Bowen, P., and O'Gorman, D. T. 2014b. Grapevine Trunk Diseases in British Columbia: Incidence and characterization of the fungal pathogens associated with esca and Petri diseases of grapevine. Plant Dis. 98:469-482.

Voordouw, G., Shen, Y., Harrington, C. S., Telang, A. J., Jack, T. R., and Westlake, D. W. 1993. Quantitative reverse sample genome probing of microbial communities and its application to oil field production waters. Appl. Environ. Microbiol. 59:4101-4114.

Zhang, N., Geiser, D. M., and Smart, C. D. 2007. Macroarray detection of solanaceous plant pathogens in the Fusarium solani species complex. Plant Dis. 91:1612-1620.

Zhang, N., McCarthy, M. L., and Smart, C. D. 2008. A macroarray system for the detection of fungal and oomycete pathogens of solanaceous crops. Plant Dis. 92:953-960. 